\title{
Gut microbiota, prebiotics, probiotics, and synbiotics in gastrointestinal and liver diseases: proceedings of a joint meeting of the Brazilian Society of Hepatology (SBH), Brazilian Nucleus for the Study of Helicobacter pylori and Microbiota (NBEHPM), and Brazilian Federation of Gastroenterology (FBG)
}

\author{
Ricardo Correa BARBUTI', Leonardo Lucca SCHIAVON² ${ }^{2}$ Cláudia P OLIVEIRA1, \\ Mário Reis ALVARES-DA-SILVA ${ }^{3}$, Lígia Yukie SASSAKI ${ }^{4}$, Maria do Carmo F PASSOS ${ }^{5}$ \\ Alberto Queiroz FARIAS'1, Luisa Leite BARROS'1, Bruno Paes BARRET06,7, \\ Gisela Bandeira de Melo Lins de ALBUQUERQUE${ }^{1}$, Amanda Mandarino ALVES', \\ Tomás NAVARRO-RODRIGUEZ ${ }^{1}$ and Paulo Lisboa BITTENCOURT ${ }^{8}$
}

ABSTRACT - Over the last years, there is growing evidence that microorganisms are involved in the maintenance of our health and are related to various diseases, both intestinal and extraintestinal. Changes in the gut microbiota appears to be a key element in the pathogenesis of hepatic and gastrointestinal disorders, including non-alcoholic fatty liver disease, alcoholic liver disease, liver cirrhosis, inflammatory bowel disease, irritable bowel syndrome, and Clostridium difficile - associated diarrhea. In 2019, the Brazilian Society of Hepatology (SBH) in cooperation with the Brazilian Nucleus for the Study of Helicobacter Pylori and Microbiota (NBEHPM), and Brazilian Federation of Gastroenterology (FBG) sponsored a joint meeting on gut microbiota and the use of prebiotics, probiotics, and synbiotics in gastrointestinal and liver diseases. This paper summarizes the proceedings of the aforementioned meeting. It is intended to provide practical information about this topic, addressing the latest discoveries and indicating areas for future studies.

HEADINGS - Gastrointestinal microbiome. Prebiotics. Probiotics. Synbiotics. Gastrointestinal diseases. Liver diseases. Practice guidelines as topic.

\section{INTRODUCTION}

There is growing evidence that microorganisms are involved in the maintenance of our health and are related to various diseases, both intestinal and extraintestinal. The systems exposed to the environment are colonized by bacteria, fungi, archaea, viruses, and even protozoa. These microscopic organisms in the respiratory system, genitourinary tract, skin, and especially digestive tract are estimated to total almost $1.5 \mathrm{~kg}^{(1)}$.

There is good evidence that our intestines can be colonized while still in the womb, even if there is no rupture of the amniotic membrane. However, colonization of the newborn does occur after birth. Vaginal and full-term delivery are conditions that most likely guarantee the development of what we call a healthy microbiota. Children born through vaginal delivery will initially be colonized by bacteria from the mother's perineum, while in cases of caesarean section, the bacteria from the hospital and the skin of the maternal abdomen will be the first to be received by the child. In addition, the stress of labor itself is considered of utmost importance for this initial colonization to occur in a healthy way. Children born through caesarean section, especially scheduled deliveries without rupture of the amniotic sac and without labor, tend to have a greater chance of developing allergic, autoimmune, degenerative, and metabolic diseases, both intestinal and extraintestinal, including obesity and cognitive disorders such as autism and depression ${ }^{(1-4)}$.

Breastfeeding is another essential variable for the development of a healthy microbiota. Although lactation formulas that mimic breast milk as much as possible are increasingly used, no product can adequately replace breast milk. Breast milk includes lactobacilli and carbohydrates known as human milk oligosaccharides (HMO). The milk of each mother has different types and amounts of microorganisms and HMOs. Such oligosaccharides function as prebiotics, stimulating the growth and development of beneficial bacteria that bind to receptors of the intestinal mucosa that could be occupied by pathogenic bacteria, thus reducing the probability of developing infections. They have important immunomodulatory

Declared conflict of interest of all authors: none

Disclosure of funding: no funding received

Universidade de São Paulo, Faculdade de Medicina, Departamento de Gastroenterologia, São Paulo, SP, Brasil. 2 Universidade Federal de Santa Catarina, Faculdade de Medicina, Departamento de Clínica Médica, Florianópolis, SC, Brasil. ${ }^{3}$ Universidade Federal do Rio Grande do Sul, Faculdade de Medicina, Departamento de Medicina Interna, Porto Alegre, RS, Brasil. ${ }^{4}$ Universidade Estadual Paulista, Faculdade de Medicina, Botucatu, SP, Brasil. ${ }^{5}$ Universidade Federal de Minas Gerais, Faculdade de Medicina, Belo Horizonte, MG, Brasil. ${ }^{6}$ Universidade do Estado do Pará, Centro de Ciências Biológicas e da Saúde, Belém, PA, Brasil. ${ }^{7}$ Centro Universitário do Estado do Pará (CESUPA), Belém, PA, Brasil. ${ }^{8}$ Hospital Português, Unidade de Gastroenterologia e Hepatologia, Salvador, BA, Brasil.

Corresponding author: Leonardo de Lucca Schiavon. E-mail: leo-jf@uol.com.br 
effects, controlling the development of our immune system. They modify the proliferation and differentiation of intestinal cells, and participate in the formation of our central nervous system. There is convincing evidence that breastfeeding and vaginal delivery have a protective effect against viral and bacterial infections and prevent the development of allergic and autoimmune diseases ${ }^{(2,5-8)}$.

During development, the child begins to ingest different types of food and develops infections, which are essential factors for increasing the number and diversity of bacteria and thus for a healthy microbiota. The first 1,000 days of life are considered the most important in the formation of the core of this microbiota. Any interference in this initial triennium may impact the rest of the child's life. Therefore, infections, drugs that interfere with immunity, vaccines, modification of acid-peptic secretion or intestinal motility, antibiotics, breastfeeding, and foods can all affect the formation of an optimal microbiota ${ }^{(9-11)}$.

Not only bacteria are important in this process. The involvement of the virome, fungome (mycome), protozoa, and even helminths has been studied. The microbiota formed is unique; no two people have the same microbiota; so we can consider this set of microorganisms as a true fingerprint of each of us. This difference is accentuated when we study populations from different regions and therefore with different life and eating habits, often within the same country ${ }^{(1,12-15)}$.

The microbiota acts in many ways, directly and indirectly, exerting protective actions, translated by the ability of "good" bacteria to protect us from infections by pathogenic microorganisms. This is accomplished by displacing pathogens (two bodies cannot occupy the same place at the same time), competing for nutrients, competing for receptors, and producing factors that can interfere with the survival of pathobiont strains. For example, the good bacteria secrete bacteriocins (natural antibiotics) and other colicins, and they generate - from the fermentation of nondigestible carbohydrates - short-chain fatty acids (SCFAs) such as butyrate, propionate, lactate, and acetate, which reduce colonic $\mathrm{pH}$, thus hindering bacterial proliferation ${ }^{(16-20)}$.

Metabolic function is exerted through the promotion of differentiation of intestinal epithelial cells, metabolization of carcinogens present in the diet, and synthesis or facilitation of the absorption of vitamins, other nutrients, and trace elements ${ }^{(16)}$.

The microbiota can also promote the digestion of various foods, such as lactose. Bacteria of the genus Lactobacillus can produce betagalactosidase and thus facilitate the breakdown of lactose, decreasing symptoms of intolerance to this disaccharide ${ }^{(21)}$. Two of the most important functions of the microbiota are its immunomodulatory effect and its role in the modulation of the gut-brain axis ${ }^{(21-29)}$.

Once healthy, we live in a state known as eubiosis, where there is balance between good and bad bacteria and the immune system of the intestinal mucosa, along with stability and diversity of our microorganisms. Specific cells of the intestinal mucosa, known as Paneth cells, are crucially important in maintaining health. They have structures known as pattern recognition receptors (PRRs), such as the Toll-like receptors (TLRs), that identify antigens present in the intestinal lumen, grouped under the name microorganismassociated molecular patterns (MAMPs). Once in eubiosis, good antigens are recognized, and there is a healthy response of the intestinal mucosa, maintaining its production of immunoglobulin $\mathrm{A}(\operatorname{IgA})$, mucus, and defensins and keeping the tight junctions fully functioning, thus ensuring intact intestinal permeability ${ }^{(22)}$.

If there is a predominance of pathogenic bacteria, or when there is loss of bacterial diversity or stability, we enter a state known as dysbiosis. This state is also recognized by intestinal PRRs that now cause the intestinal mucosa to act in an unhealthy way, decreasing the production of mucus, IgA, and defensins and causing the tight junctions to stop functioning properly. This promotes an increase in intestinal permeability, allowing the passage of bacterial and food antigens, bacterial products and other microorganisms to deeper layers of the intestinal mucosa. As a consequence, cells of the immune system are attracted to this site (mast cells, for example), releasing several proinflammatory cytokines, which in turn attract more inflammatory cells, thus triggering an inflammatory cascade ${ }^{(2)}$. This state is "perceived" by afferent nerve fibers, which in turn transmit this information to our central nervous system, which then filters and modulates these stimuli, sending an efferent response, directly through the nerve (vagus nerve) and also concomitantly through the hypothalamic-pituitary-adrenal axis, modulating intestinal motility, secretion, and sensitivity, in addition to promoting systemic, metabolic, and biochemical actions capable of modifying our whole-body physiology ${ }^{(9,23-25)}$.

These same cytokines produced in the submucosa of the intestine can reach the blood vessels, reaching the blood-brain barrier, modulating the action of the central nervous system, by altering, for example, the expression of several receptors, such as serotonin receptors, thus promoting or modulating mood disorders, chronic fatigue, loss or increase of appetite, etc ${ }^{(26,27)}$.

Some bacteria can produce neurotransmitters, amino acids, and hormones that, once absorbed, are transported by the circulatory system, substantially changing the functions of our body. The microbiota is also able to modulate the expression of several intestinal and extraintestinal receptors, promoting modifications in various systems ${ }^{(27,28)}$

Our intestine also has many neuroendocrine cells, some in close contact with the intestinal lumen, whose functions include the release of a wide variety of neurotransmitters that can directly alter the gut-brain axis. More than 30 hormones have already been described in the intestine, and almost $95 \%$ of all of our serotonin is found at this site ${ }^{(29-31)}$. This whole process can be modified by several factors, including aging, with different consequences ${ }^{(32,33)}$.

The microbiota can be modified by various mechanisms. The most common way is through the diet. Important dietary components that can promote changes in the microbiota are fibers. Some of these nondigestible carbohydrates, especially soluble fibers, can serve as food for good bacteria, so they are called prebiotics. For each bacterium, there is an ideal prebiotic, and the so-called "prebiotic index" can be calculated for each type of bacterium. Prebiotics, once fermented by intestinal bacteria, yield SCFAs, especially butyrate, which favors absorption of water and electrolytes, coordinates intestinal motility, improves rectal compliance, accelerates repair of enterocytes, promotes intestinal differentiation, has an anti-inflammatory effect, and reestablishes intestinal permeability ${ }^{(19,34-37)}$.

The SCFAs are absorbed, and once in the circulation, they can modulate the blood-brain barrier and positively affect the arrival of chemically active substances to the CNS. The SCFAs bind to specific receptors of the intestinal mucosa (free fatty acid receptors) and interfere directly in the gut-brain axis and, by also binding to intestinal TLRs, can control several factors related to our metabolism in general. There is robust evidence showing they alter the release of ghrelin, leptin, PYY, GLP-1, GLP-2, etc. They can also reduce the adherence of pathogenic strains to the intestinal 
wall and stimulate the action of NK cells and phagocytic activity. They modulate the immune response via the TLR activity of dendritic cells and can reduce inflammation through the secretion of anti-inflammatory cytokines such as interleukin (IL)-10 and the reduction of inflammatory cytokines such as IL-1 beta and IL-6. Antimitotic effects are also described ${ }^{(9,27,37,38)}$.

Bacterial fermentation also causes gas production, which by itself can result in distension and discomfort while simultaneously interfering with intestinal motility. For example, methane is directly related to cases of constipation ${ }^{(39)}$.

Bacteria ingested through the diet can exchange genetic material with our intestinal bacteria and thus modify their function (a phenomenon known as horizontal or lateral gene transfer) ${ }^{(40)}$. Dietary changes can quickly change the microbiota, and these changes might be beneficial or not ${ }^{(41)}$.

Another way of changing our microbiota is through physical activity. Regular exercise, in addition to improving mood and preventing cognitive decline, modifies mucosal immunity and directly interferes with the gut microbiota, increasing its diversity, decreasing pathobiont strains, producing antioxidant agents, and increasing SCFA production ${ }^{(42-44)}$.

Fecal microbiota transplantation clearly modifies the microbiota, and its use in clinical practice is limited to the treatment of colitis secondary to Clostridioides difficile that does not respond to metronidazole or vancomycin. Ongoing protocols attempt to study this method of manipulation of the microbiota for the treatment of inflammatory bowel disease (IBD), functional diseases, cirrhosis, depression, obesity, and autoimmune diseases. It is very important to note that fecal microbiota transplantation involves the introduction of not only of bacteria but also of all fecal components into the recipient's intestine, which may include microorganisms and varying amounts of proteins, cytokines, carbohydrates, etc. For these reasons, the safety of fecal transplantation should be very carefully analyzed ${ }^{(45)}$.

Any drug that interferes with intestinal motility and secretion, immunity, or peptic acid secretion may also modify the microbiota. These include drugs such as proton pump inhibitors (PPIs), antidepressants, chemotherapeutic drugs, and diuretics. However, antibiotics are undoubtedly the agents that have a greater impact, as classic dysbiosis promoters. However, antimicrobials can be used positively for manipulation of the microbiota, such as for intestinal and extraintestinal infections or, for example, small intestinal bacterial overgrowth syndrome. The use of these drugs indiscriminately, especially during the formation of the microbiota, i.e., in the first 1,000 days of life, can impact the rest of our lives, for example by promoting greater predisposition to obesity or excessive thinness, and allergic and autoimmune diseases ${ }^{(46-48)}$.

Finally, another way to manipulate the set of intestinal microorganisms is supplementation with probiotics (living organisms that, when consumed in adequate amounts, have a positive effect on the health of the host). The probiotics may be bacteria or fungi and must therefore be alive and in an adequate number at their site of action, the intestinal lumen. For this to happen, they must resist passage through the stomach and small intestine because hydrochloric acid, pepsin, bile salts, and pancreatic enzymes have a strong bactericidal effect. It is very important that they be preserved and transported in an appropriate manner. Thus, probiotics should be kept refrigerated, and when they are not, there may be loss of viable strains. Some microorganisms cannot be transported by aircraft because they cannot withstand the variation in atmospheric pressure. The preservation of probiotics may also be influenced by the climate zone, such that there may be differences in viability and action in different regions of the planet ${ }^{(1,49)}$.

For the development of a probiotic, a long period of study must be adopted that includes the selection of strain with probiotic potential, the study of its behavior, and the testing of its safety and efficacy in vitro and then in vivo, including studies in test animals and subsequently in humans ${ }^{(50)}$.

After this process, probiotics go through a multiplication process so that they can be commercialized. It is very important for the manufacturer to control for possible spontaneous or phage-induced mutations because these factors can interfere with the efficacy and especially in the safety of the supplemented strain(s) ${ }^{(49)}$.

Probiotics are not all the same, and although there may be characteristics common to similar genera and species - the same way that we all are Homo sapiens - there is great variation between strains. Bacteria of the same species but of different strains can have completely different responses ${ }^{(1,51,52)}$.

The action of probiotics can vary according to the strain, genetic characteristics of the PRR, climate, temperature, drugs taken, and foods eaten, and with the rest of the recipient's microbiota. The combination of different strains in a single product does not necessarily mean a better clinical response. Different strains can compete for nutrients and receptors, can produce bacteriocins that kill other strains, and may have different characteristics regarding the interaction with food and drugs and survival in different climate regions. The action of probiotics may also vary according to the matrix used, i.e., probiotics in fermented milks may function differently when supplied in capsules. Finally, the use of synbiotics (combination of prebiotics with probiotics) is not necessarily better than the use of probiotics alone because there is an ideal prebiotic for each probiotic ${ }^{(49,52)}$.

The most important message is that the probiotic effect is strain specific and should be studied as such. The more studied the strain is, the more we can confirm its indications and efficacy in different clinical situations. The strains supplied together should be studied together.

\section{MICROBIOTA AND IMMUNITY}

Since the end of the nineteenth century and the beginning of the twentieth century, the increase in the prevalence of immunemediated diseases worldwide has become more evident, at a growth rate higher than the arithmetic growth rate of the population. Many studies point to the relationship of humans with their intra- or extracorporal environment as one of the main factors underlying this epidemic. Environmental and climate changes, lifestyle and diet, water quality, the establishment of good hygiene practices, and automation of the agricultural process with population migration to urban areas are some of the transforming factors leading to the prevalence of noncommunicable diseases in the last 150 years ${ }^{(53)}$.

In the human gut, we find all three domains of living organisms: Archaea, Bacteria, and Eukarya. In the vast majority of humans, the Bacteria domain is represented mainly by the divisions Firmicutes, Bacteroides, and, to a lesser extent, Proteobacteria. Variations in bacterial species can occur, especially in unrelated individuals, due to vertical transmission, i.e., the colonization from the mother to the child ${ }^{(54)}$. The gut microbiota undergoes significant changes from birth to old age, reconfiguring its metagenomic profile in response to dietary changes and the physiological and immunological needs 
that arise throughout life. This plasticity is a fundamental strategy to face the changes in lifestyle and eating habits that have occurred throughout our history, from the hunters of the Paleolithic era, through the Neolithic agricultural era, to the modern Western society. This situation was only possible through a process of coevolution of the bacterial communities and the host over time, where both parties benefited and still benefit from each other, begetting a situation of mutual coexistence (mutualism). Microorganisms benefit from the stable intestinal environment and the nutrients that arrive there, while the host benefits from the uptake of products derived from the fermentation of nondigestible fibers, such as SCFAs, which are responsible for approximately $10 \%$ of the energy required for the functioning of the body, through the production of vitamins $\mathrm{K}$ and B12, and from the defense against potential pathogens, through competitive exclusion and immunomodulation phenomena ${ }^{(55)}$.

The diversity of the human microbiota is also shown by the difference between the bacterial populations found in the intestinal lumen relative to those adhered to the epithelium (biofilm), which seem to have a greater beneficial function - due to the greater contact - either in the absorption of nutrients or in the activation of the innate immune response ${ }^{(54)}$.

Before birth, in utero, the fetus finds perfect conditions for its development: a proper diet, a perfect temperature, a pathogen-free environment, and a mechanism of immune tolerance (Th2 dependent) that prevents it from being rejected by the maternal organism. Recent studies have revealed the presence of microorganisms in the amniotic fluid in the fetal membranes, umbilical cord, placenta, and meconium. The meconium exists in two distinct periods: the first less diversified and with a predominance of bacteria of the family Enterobacteriaceae; the second later and more diversified, with a predominance of bacteria of the phylum Firmicutes, especially lactic acid bacteria. This bacterial population differs from the profile found in the vagina, skin, or feces of pregnant women, suggesting that this population of meconium bacteria has a uterine origin, as it resembles the profile in the amniotic fluid. In this sense, it is believed that colonization of the fetal gastrointestinal tract may occur in utero, through the swallowing of the amniotic fluid ${ }^{(56,57)}$. At birth, even before taking his/her first breath, the child is already being colonized. In the early hours, due to the presence of oxygen, there is a predominance of aerobic bacteria, such as streptococci and $E$. coli. Later, as oxygen is consumed, strictly anaerobic bacteria such as Bifidobacteria, Bacteroides, and Clostridium prevail ${ }^{(58)}$.

The establishment of the microbiota lasts until the third year of life, in the first 1,000 days, and thus the correction of possible deviations in the establishment of this "metabolic" organ during this period can promote the development and future health of the child ${ }^{(59)}$. Two conditions are essential for the establishment of the appropriate microbiota in the first hours of life: vaginal delivery and exclusive breastfeeding. These two factors, however natural they may seem, are not very common these days. Breast milk contains a number of bioactive factors and immunostimulants, which together with the gut microbiota regulate the morphophysiological maturation of the intestine. For example, HMO, present in large concentrations in colostrum, serve as binding sites for microorganisms beneficial to the microbiota, such as Bifidobacterium spp., and reduce colonization by possible pathogens ${ }^{(59)}$. A disturbance in this colonization sequence, whether due to pre-, intra-, or postgestational factors, may be related to a potential long-term risk to the health of this individual because some of these diseases of modern civilization have their genesis in developmental failures or failures in the function of the immune system. These immune system disorders, in turn, may result from the presence of dysbiosis, where there is an imbalance of the human microbiome, either as a decrease in symbiotic bacteria or as an increase in pathogenic bacteria ${ }^{(58)}$.

The association between the gut microbiota profile, with a predominance of Clostridium, and the risk of developing allergic diseases, such as atopic dermatitis, at 5 and 13 months has been reported. These microbial profile is also influenced by the number of contacts in the environment (number of siblings), which may suggest participation of the gut microbiota in the mechanism of the hygiene hypothesis ${ }^{(60)}$.

Both the intestine and the skin are sites where there is a constant dialogue between the immune system and microorganisms. The molecular mechanisms that prevent a deleterious inflammatory response and that enable tolerance are still not fully known. Most likely, this immune tolerance mechanism results from the increase in the Th1-dependent lymphocyte response after birth, which is due to the onset of antigen stimulation, especially by nonpathogenic microorganisms found in the intra- or extracorporal environment. A reduction in this Th1-dependent response, with consequent maintenance and escalation of the Th2 response, is found in children at risk for atopic diseases, such as asthma, in addition to those with reduced responses to vaccine antigens and greater susceptibility to respiratory infections ${ }^{(61)}$.

It is postulated that microbial products, such as those found in the normal microbiota, with MAMPs associated with PRRs, such as $T L R$, are key elements for the onset of the tolerogenic innate immune response, with maturation and activation of regulatory $\mathrm{T}$ cells and/ or the Th1 profile, which together modulate the immune response through the synthesis of cytokines such as IL-10 and TGF-beta, which are negatively correlated with the development of the atopic profile. More recently, a group of small, noncoding RNA-based molecules called microRNAs has been identified in breast milk and other secretions; those molecules play a role in gene regulation at the posttranscriptional level. They are abundant in colostrum and seem to influence the gastrointestinal and immunological development of newborns but have not been specifically or significantly associated with the prevention of atopic dermatitis in newborns of mothers who ingested probiotics in the perinatal period ${ }^{(61,62)}$.

Thus, it is possible that the origin of immune-mediated processes, such as allergic diseases, goes back to the earliest phases of life and derives from a complex interaction between genetic susceptibility and early environmental contact, either in the intrauterine period through maternal exposure and experiences or in the immediate postnatal period, producing phenotypic differences between those who will and will not develop such immunological imbalances ${ }^{(61)}$.

\section{ROLE OF MICROBIOTA IN LIVER DISEASES}

\section{Non-alcoholic fatty liver disease}

Non-alcoholic fatty liver disease (NAFLD) is one of the most common forms of liver disease, primarily related to the global increase in the prevalence of obesity, type 2 diabetes mellitus (T2DM) and metabolic syndrome (MS). It is a complex disease that involves environmental factors and genetic predisposition ${ }^{(63)}$. NAFLD encompasses a range of liver changes ranging from fat accumulation in $\geq 5 \%$ of hepatocytes without inflammation or fibrosis (simple steatosis), to cases of nonalcoholic steatohepatitis (NASH), cirrhosis, and hepatocellular carcinoma (HCC), in the absence of significant alcohol consumption ${ }^{(64)}$. 
NAFLD is associated with MS components: T2DM, insulin resistance (IR), systemic arterial hypertension (SAH), central obesity, and dyslipidemia. It may also be associated with surgical procedures such as jejunoileal bypass, protein deficiency, prolonged parenteral nutrition, endocrine diseases, use of medications, and exposure to toxins ${ }^{(65,66)}$. A sedentary lifestyle, high intake of foods high in fat and fructose, obesity, metabolic disorders, hormonal status, and genetic background have also been described as responsible for the development of NAFLD ${ }^{(67)}$.

The physiopathology of NAFLD has not yet been fully elucidated. Approximately $10 \%-25 \%$ of patients with NAFLD develop $\mathrm{NASH}^{(68)}$, and the factors responsible for the progression of steatosis to NASH remain unknown and are the subject of extensive research. Currently, most authors believe in the hypothesis of multiple hits. The first hit is closely associated with multiple metabolic abnormalities, IR being the initial condition for the accumulation of fatty acids in hepatocytes, as it favors lipogenesis and inhibits lipolysis, resulting in an excessive increase in the supply of fatty acids in the liver, followed by a sequence of events (multiple hits), such as increased oxidative stress, stress of the endoplasmic reticulum, mitochondrial dysfunction, and chronic endotoxemia ${ }^{(69)}$.

Endogenous factors such as the gut microbiota may also contribute to the development of NAFLD. Increased intestinal permeability and small intestinal bacterial overgrowth (SIBO) are frequently observed in obese patients. These changes induce hepatic lesions by increasing the production of lipopolysaccharides derived from intestinal Gram-negative bacteria, activating NF- $\varkappa \mathrm{B}$ and the production of TNF- $\alpha$, which are associated with the progression of steatosis to $\mathrm{NASH}^{(70-72)}$. In addition, increased intestinal permeability leads to bacterial translocation, allowing the endotoxins produced by these bacteria to reach the portal vein by activating TLRs in hepatocytes ${ }^{(73)}$, decreasing the secretion of the fastinginduced adipocyte factor (FIAF) and increasing the activity of lipoprotein lipase (LPL) and hepatic triglyceride accumulation ${ }^{(74,75)}$.

The expression of TLRs in different cell types is critical in the pathogenesis of chronic liver diseases. Specifically, TLR2, TLR3, and TLR 4 are highly expressed in Kupffer cells and respond to the stimulation by intestinal endotoxins, leading to rapid production of TNF- $\alpha$ and IL-6. Furthermore, TLRs are expressed in bile epithelial cells, stellate cells, hepatocytes, and hepatic sinusoidal endothelial cells ${ }^{(76)}$, being key for the pathophysiological processes that generate multiple liver diseases, such as viral hepatitis, HCC, NAFLD, cirrhosis, and fibrosis ${ }^{(77)}$.

Recent studies in human and animal models have shown that the gut microbiota is an important factor for energy storage and contributes to the increase in adiposity and the development of NAFLD ${ }^{(78,79)}$. Low proportions of Bacteroidetes and high proportions of Prevotella and Porphyromus have been found in patients with NAFLD, favoring a greater extraction of dietary energy and fat accumulation compared to individuals without NAFLD ${ }^{(80,81)}$. A recent study by Machado et al. ${ }^{\left({ }^{(2)}\right)}$ showed an increase in the amounts of Lactobacillus, Escherichia, and Streptococcus, as well as a decrease in Ruminococcaceae and Faecalibacterium prausnitzii in patients with NAFLD. Another recent study, by Boursier et al. ${ }^{\left({ }^{(3)}\right)}$, showed that the reduced amount of Bacteroides was independently associated with NASH and that the prevalence of Ruminococcus was associated with fibrosis stage $\geq F 2$. Obesity is associated with SIBO and increased intestinal permeability when compared to nonobesity without NAFLD ${ }^{(84)}$. However, the role of these microorganisms in the progression of NAFLD to NASH in normal-weight patients with NASH needs to be further explored. It is important to note that most studies on patients with NAFLD have several limitations, such as a lack of a systematic liver biopsy protocol, heterogeneous populations (adults vs. children), and characterization of gut microbiota by different methods, such as polymerase chain reaction (PCR) and pyrosequencing ${ }^{(85,86)}$.

One of the mechanisms by which the gut microbiota contributes to the development of NAFLD can be the increase in the number of ethanol-producing bacteria (e.g., Escherichia coli) ${ }^{(80)}$. The ethanol produced by these bacteria contributes to physiological and morphological changes in the intestinal barrier associated with SIBO, increasing intestinal permeability and, thereby increasing the passage of endotoxins from the intestinal lumen to the portal blood. This leads to an increase in the production of reactive oxygen species, even in the absence of alcohol consumption. It was found that a diet rich in refined sugar can lead to increased levels of alcohol in the blood and that the endogenously synthesized ethanol is eliminated through the alcohol dehydrogenase pathway in the liver. This enzyme converts alcohol into acetaldehyde, which, even at small concentrations, is toxic to the body ${ }^{(87,88)}$.

Zhu et al. ${ }^{(89)}$ examined the composition of the gut microbiota and the ethanol levels in the blood of obese and eutrophic patients with NASH. Compared to obese individuals without liver disease, NASH patients showed differences in the proportions of the phylum Proteobacteria, the family Enterobacteriaceae, and the species E. coli. Some of these changes included more alcohol-producing bacteria, associated with a significant increase in ethanol levels in NAFLD patients compared to obese patients without NAFLD. In addition, increased ethanol levels were specifically correlated with the presence of NASH. In summary, these results suggest that the production of ethanol by the gut microbiota may contribute to the development of NAFLD and its progression to $\mathrm{NASH}^{(89)}$.

Another product of the metabolization of nutrients by bacteria that can be toxic to the liver is the trimethylamine $\mathrm{N}$-oxide (TMAO) compound. The gut microbiota can promote the conversion of choline into trimethylamine (TMA), which will then reach the liver through the portal circulation and be converted into $\mathrm{TMAO}^{(82)}$. The increase in the production of this compound leads to a decrease in the export of hepatic VLDL and modulation of bile acid synthesis, with detrimental effects to the liver, such as increased liver fat deposition, inflammatory and oxidative lesions, and decreased glucose metabolism ${ }^{(90)}$.

A recent Brazilian study showed that thin patients with NASH have a different gut microbiota composition than patients who are overweight/obese without NAFLD. Fibrosis score $\geq 2$ was also associated with the gut microbiota composition, but the intake of macronutrients and calories was not associated with specific differences in the composition of fecal intestinal microorganisms ${ }^{(91)}$. However, these data need to be confirmed by larger studies, including patient populations stratified by sex and eating habits.

\section{Alcoholic liver disease}

Among the causes of chronic liver disease, alcoholic liver disease (ALD) is the most frequently associated with hospital admissions, with significant costs and high mortality. However, little attention is still paid to the disease, given that it is the one on which there are the fewest articles published as well as the fewest presentations in major hepatology conferences ${ }^{(92)}$.

Recently, the European Association for the Study of the Liver (EASL) launched the Study of Alcohol Related Liver Disease in 
Europe (SALVE) consortium, aiming to collect information on ALD, such as clinical and molecular aspects, but also to define a new diagnostic score for the disease. ALD is an old and prevalent disease, but only now its diagnostic criteria are being defined, illustrating the little importance that has been given to it over the years. It is predicted that this may change in the near future, and one of the reasons is that several characteristics associated with ALD are similar to those of nonalcoholic fatty liver disease (NAFLD), including natural history (steatosis, steatohepatitis, and fibrosis), genetic factors (e.g., PNPLA3 gene polymorphisms), and the presence of intestinal dysbiosis. Alcohol-induced intestinal dysbiosis, like the obesity-induced form, leads to the activation of the systemic inflammatory cascade via the MAMP-inflammasome system, which contributes decisively to the progression of the disease $^{(93-95)}$ (FIGURE 1).

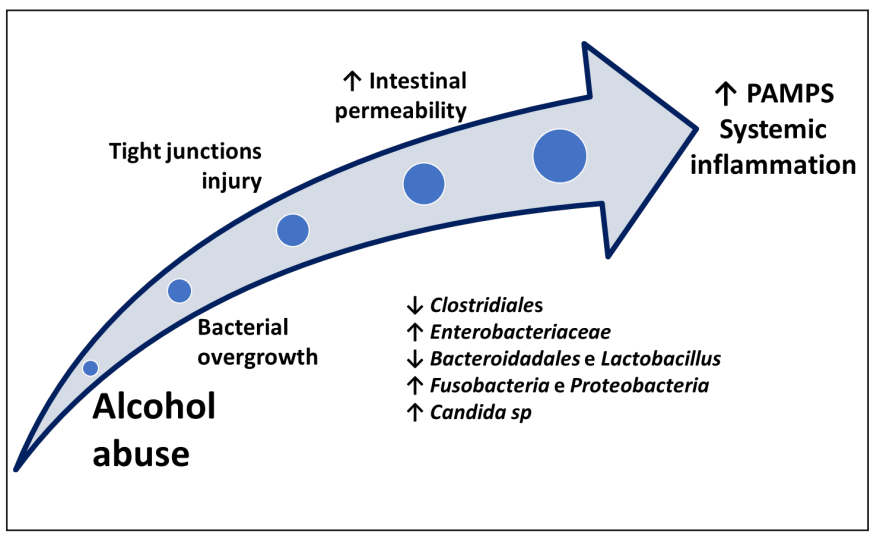

FIGURE 1. Alcohol-induced intestinal dysbiosis. PAMPs: pathogenassociated molecular patterns.

The changes associated with intestinal dysbiosis in patients with ALD are more marked in patients with alcoholic hepatitis, usually cirrhotic, where the alcohol-induced dysbiosis is compounded by the dysbiosis related to cirrhosis itself ${ }^{(95)}$. The therapeutic options in alcoholic hepatitis are limited, and a recent Cochrane review suggests that no findings support the use of any drugs for the treatment of the syndrome, including corticosteroids ${ }^{(96)}$. Thus, there is a need for new agents for the treatment of ALD. The potential targets include the action in the gut microbiota, which includes probiotics, prebiotics, antibiotics, and microbiota transplantation ${ }^{(95,97)}$. However, no studies have effectively supported its application in humans.

The clinical importance of ALD, the relevance of intestinal dysbiosis, and the lack of effective therapeutic measures opens the door for conducting experimental studies in this field. Conversely, the use of rats for the evaluation of ALD is discussed because these animals not only have aversion to alcohol but are resistant to its effects. Zebrafish, on the other hand, could be used as an animal model of $\mathrm{ALD}^{(98,99)}$. A recent Brazilian study in zebrafish evaluated the effects of exposure to alcohol in the aquarium water, fed or not with probiotics. In the treated animals, there was a decrease in hepatic steatosis, a decrease in systemic inflammation assessed by the activation of inflammasomes, and an increase in cldn15a expression, suggesting a protective effect of the probiotic ${ }^{(100)}$.

The microbiota is probably a viable path to follow, not only for better understanding of the pathogenesis of ALD but also for its management, but it is still early to recommend any intervention in dysbiosis as a form of ALD control, including probiotics.

\section{Decompensated cirrhosis}

Liver cirrhosis may result from different mechanisms of injury, including chronic infection by hepatitis $\mathrm{C}$ and $\mathrm{B}$ viruses, NAFLD, ALD, and autoimmune liver diseases. The disease is histologically characterized by diffuse nodular regeneration, dense fibrous septa with subsequent parenchymal extinction, and structural collapse ${ }^{(101)}$. Liver cirrhosis is associated not only with a significant impact on survival but also with significant morbidity and high costs ${ }^{(102)}$.

In recent years, evidence has emerged that the gut microbiota is altered in cirrhosis, regardless of its etiology, promoting an imbalance or dysbiosis, possibly implicated in the development of clinical complications or influencing the severity of liver disease.

Bacterial proliferation may be affected by various anatomical and physiological traits of the gastrointestinal tract, such as peristalsis, gastric acidity, the amount and toxic effects of bile, the presence of bacterial proteolytic enzymes, mucus production, secretory $\operatorname{IgA}$ level, and ileocecal valve pressure. In addition, external factors, such as diet, use of antibiotics, and various environmental factors may affect the composition of the gut microbiota ${ }^{(103-106)}$. In dysbiosis, quantitative (SIBO) and qualitative changes to the gut microbiota occur. SIBO, defined by $>10^{5}$ colony-forming units $(\mathrm{CFU}) / \mathrm{mL}$ and/or the presence of colonic bacteria in the jejunal aspirate, is present in $48 \%-73 \%$ of patients with cirrhosis ${ }^{(107,108)}$. Factors such as dysmotility, decreased biliary flow, and lower secretion of $\operatorname{IgA}$ and enteric antimicrobial peptides have been implicated in its pathogenesis ${ }^{(109,110)}$.

In cirrhosis, the gut microbiota composition undergoes taxonomic changes due to the decreases in the proportions of autochthonous Lachnospiraceae, Ruminococcaceae, and Clostridiales, taxa that are beneficial to the host. There is a relative increase in potentially pathogenic bacteria such as Enterobacteriaceae, Staphylococcaceae, and Enterococcaceae ${ }^{(111,112)}$. Dysbiosis has negative consequences due to reduced production of SCFAs, which are important for the integrity of colonocytes and the local anti-inflammatory effects on the mucosal barrier, in addition to promoting lower production of antimicrobial peptides that reduce colonization by pathogenic bacteria. There is a correlation between the cirrhosis/dysbiosis ratio (Firmicutes/Bacteroidetes ratio) and the degrees of clinical decompensation and endotoxemia ${ }^{(113)}$. Dysbiosis, combined with changes in the mucosal barrier (increased intestinal permeability), contributes to the endotoxemia observed in patients with cirrhosis ${ }^{(114)}$.

In fact, bacterial translocation is an event strongly related to endotoxemia and is mainly due to changes in the integrity of the mucosal barrier in cirrhosis. The innate immune system represents the first line of defense against pathogens, which are recognized by a system that detects highly conserved motifs present in bacteria (MAMPs), through their interaction with PRRs located on the cell surface and in the endosomal compartment. These include TLRs, which recognize triacyl and diacyl lipase, flagellin, and microbial lipopolysaccharides, triggering subcellular responses that result in the production of proinflammatory cytokines and endotoxemia. Bacterial or bacterial product translocation may occur through three distinct cirrhosis pathways: a) via dendritic cells; b) via inflamed or damaged epithelium, with increased permeability; and c) via mast cells in contact with Peyer's patches, which favor the access and contact of bacterial products with antigen-presenting cells ${ }^{(107)}$.

Studies indicate that the microbiota composition is associated with the severity and development of clinical complications of cirrhosis, particularly hepatic encephalopathy (HE) and spontaneous 
bacterial peritonitis (SBP). The most robust data published so far refer to the participation of intestinal dysbiosis in the development of HE. Dysbiosis favors increased production of ammonia, mercaptans, and phenols and exacerbation of the endotoxin-mediated inflammatory response. A metagenomic study of patients with cirrhosis showed that bacterial genes involved in the incorporation or release of nitrate into or from the ammonia molecule, denitrification, and biosynthesis of gamma-aminobutyric acid are highly represented ${ }^{(115)}$. This observation is in line with the demonstration of the enrichment of the modules of the transport systems, particularly manganese, in the microbiota of patients with cirrhosis ${ }^{(116)}$.

\section{Acute-on-chronic liver failure}

In recent years, the concept of acute-on-chronic liver failure (ACLF) has been coined to identify patients with chronic hepatic diseases, particularly cirrhosis, who progress to acute deterioration of liver function, precipitated by liver injury or extrahepatic factors $^{(117)}$. In this time, a growing number of studies addressing different definitions, criteria, prognostic scores and biomarkers, and pathophysiological and clinical aspects of ACLF have been published. The two most commonly used ACLF definitions are those of the North American Consortium for the Study of End-Stage Liver Disease (NACSELD) and the EASL-CLIF consortium. The definition of the NACSELD consortium uses the following criteria for the definition of organ failures: 1) brain failure: encephalopathy grade III or IV; 2) circulatory failure: MAP $<60 \mathrm{mmHg}$ or reduction greater than $40 \mathrm{mmHg}$ in the basal systolic BP despite volume resuscitation; 3) respiratory failure: need for mechanical ventilation; and 4) kidney failure: need for dialysis ${ }^{(118)}$. In a study of 2675 hospitalized cirrhotic patients, NACSELD-ACLF, defined as two or more organ failures, was found in approximately $10 \%$ of patients, with a 30-day overall survival of 59\% in those with ACLF and $93 \%$ in individuals without ACLF(119). The definition proposed by the EASL-CLIF consortium is based on a modification of the SOFA score, called CLIF-SOFA, and was proposed in the CANONIC study that included 1343 cirrhotic patients hospitalized due to acute decompensation of the disease in 29 hepatology centers. ${ }^{(120)}$ Based on these criteria, ACLF could be classified as absent and grades 1 , 2 , and 3 (TABLE 1), and they had 90-day mortality rates of $14 \%$, $41 \%, 52 \%$, and $79 \%$, respectively ${ }^{(120)}$.
ACLF is considered a late event in the natural history of cirrhosis and is related to a pattern of immune dysfunction similar to that observed in sepsis. Elevated levels of inflammatory cytokines are observed in ACLF, even in the absence of infections ${ }^{(121)}$. Paradoxically, these patients also have marked immunosuppression that is related to the occurrence of secondary infections ${ }^{(122)}$. Changes in the gut microbiota are expected in cases of advanced organ dysfunction in cirrhotic patients, either as a contributing cause or as a consequence of profound immune changes. In fact, a study of 219 cirrhotic patients, 44 of whom were hospitalized, showed progressive changes in the gut microbiota according to the progression of cirrhosis $^{(113)}$. In that study, patients with ACLF showed a reduction in Gram-positive Clostridiales and Leuconostocaceae ${ }^{(113)}$. In another study that also evaluated fecal samples, 79 patients with ACLF were compared to 50 healthy controls ${ }^{(123)}$. ACLF was related to decreased microbial diversity and dysbiosis, with a decrease in the abundance of Bacteroidaceae, Ruminococcaceae, and Lachnospiraceae but an increase in the abundance of Pasteurellaceae, Streptococcaceae, and Enterecoccaceae ${ }^{(123)}$. Interestingly, an increase in the abundance of the family Pasteurellaceae was related to mortality in patients with $\mathrm{ACLF}^{(123)}$. More recently, in a multicenter study including 181 patients with cirrhosis, there was an increase in the abundance of members of the phylum Proteobacteria, and this change was associated with extrahepatic organ failure, ACLF, and death, independent of other clinical factors ${ }^{(124)}$.

These findings suggest that changes in the gut microbiota are pronounced in the presence of advanced decompensation of cirrhosis and ACLF. Dysbiosis seems to be related to both progression to organ dysfunction and prognosis in patients hospitalized due to acute decompensation. However, the currently available evidence do not allow us to establish a clear causal nexus between the observed associations. New studies are needed to clarify the relationship between the microbiome composition and complications of cirrhosis and to investigate possible therapeutic interventions in patients with ACLF.

\section{Use of prebiotics, probiotics, and synbiotics in liver diseases}

Evidence of the relationship between microbiota and liver diseases is growing. A search in the PubMed database in May

TABLE 1. Definition of ACLF as proposed by the EASL-CLIF consortium and its prognostic impact.

\section{Criterion}

Any of the following:

No ACLF

(1) Absence of organ failure

(2) Failure of one organ (non-kidney) with $\mathrm{Cr}<1.5 \mathrm{mg} / \mathrm{dL}$ and without encephalopathy

(3) Brain failure alone (with $\mathrm{Cr}<1.5 \mathrm{mg} / \mathrm{dL}$ )

Any of the following:

(1) Kidney failure alone

ACLFgrade 1 (2) Liver, coagulation, circulatory, or respiratory failure with Cr between $1.5 \mathrm{mg} / \mathrm{dL}$ and $22.1 \%$

$1.9 \mathrm{mg} / \mathrm{dL}$ and/or mild/moderate encephalopathy;

(3) Brain failure with $\mathrm{Cr}$ between $1.5 \mathrm{mg} / \mathrm{dL}$ and $1.9 \mathrm{mg} / \mathrm{dL}$

ACLFgrade 2 Failure of two organs

ACLFgrade 3 Failure of three or more organs
$32.0 \%$

$52.3 \%$

$\begin{array}{ll}28 \text {-day } & \text { 90-day } \\ \text { mortality } & \text { mortality }\end{array}$

$4.7 \%$

$14.0 \%$

$76.7 \%$

$79.0 \%$

Source: adapted from Jalan et al., 2014. Criteria for organ failure: Liver: bilirubin $\geq 12.0 \mathrm{mg} / \mathrm{dL}$; kidney: creatinine $\geq 2.0 \mathrm{mg} / \mathrm{dL}$; brain: encephalopathy grades 3 or 4 ; coagulation: INR $\geq 2.5$; circulatory: use of vasopressors; respiratory: $\mathrm{PaO}_{2} / \mathrm{FiO}_{2}$ ratio $\leq 200$ or $\mathrm{SaO}_{2} / \mathrm{FiO}_{2}$ ratio $\leq 214$ or mechanical ventilation (except for hepatic coma). 
2019 found more than 750 articles on the subject (FIGURE 2). In fact, the gut-liver axis is an anatomical and functional unit, and intestinal dysbiosis significantly affects the hepatic immune response. Gut-derived inflammation, through PAMPs, lipopolysaccharides, and even viable pathogens, acts as a promoter of liver injury, which includes the progression of inflammation to fibrosis, cirrhosis, portal hypertension (PH), and HCC. Thus, intervention in the gut with the use of probiotics especially, but also prebiotics and synbiotics, has been undertaken in several diseases, such as NAFLD and cirrhosis.

Since the publication of the first randomized controlled trial $(\mathrm{RCT})^{(125)}$, several attempts have been made to evaluate the usefulness and safety of these compounds in the progression of liver disease. Despite the many publications, the use of probiotics in clinical practice is still controversial ${ }^{(94)}$. We performed a systematic review of published articles on the subject in databases such as PubMed, Medline, Cochrane, Lilacs, and Scopus in May 2019 to answer the following question: Is the use of prebiotics, probiotics, and synbiotics in liver diseases safe and effective?

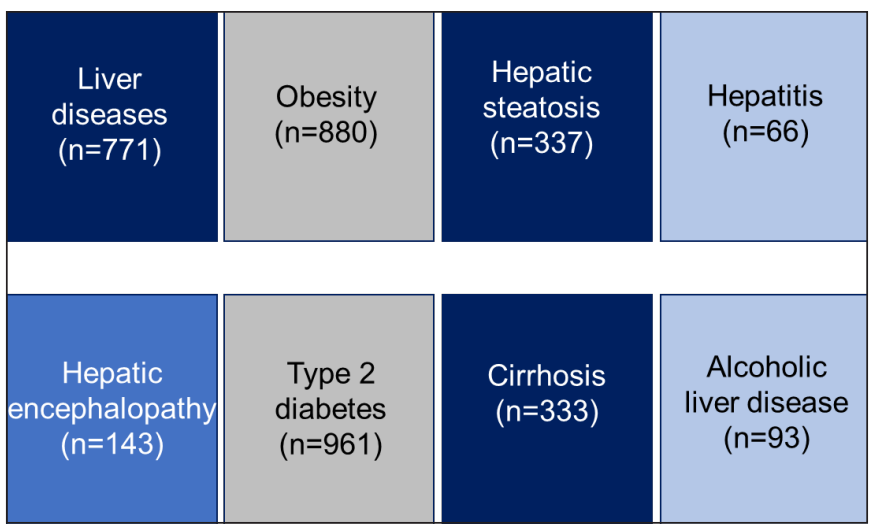

FIGURE 2. Published articles on microbiota in liver disease (PubMed, May 2019).
The key words used were probiotics, prebiotics, synbiotics, psychobiotics, postbiotics, microbiota, and liver diseases. FIGURE 3 shows the search results. We evaluated all abstracts and selected the articles on humans that met the following inclusion criteria: randomized controlled trials in various liver diseases, compared or not to placebo, in any language. Next, the full version of each article was evaluated according to the purpose of the review.

Of the 50 selected randomized controlled trials, 35 were published as of 2013, and 25 were published from 2014 onwards. The profile change between the articles was noteworthy: The first group focused more on complications of cirrhosis, especially hepatic encephalopathy (HE), and the second group on NAFLD. TABLE 2 summarizes some of the main studies published since 2014.

In general, the studies were still limited, with small sample sizes and the use of substitute outcomes. Probiotics varied in terms of their presentation, the doses, and times of use. Safety analysis was rarely mentioned in the studies ${ }^{(94,126)}$. The effects, taken together, and limited to the most studied clinical situations

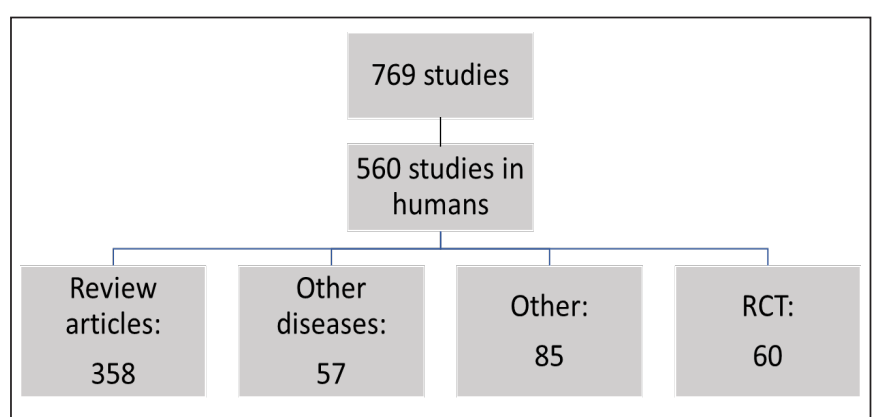

FIGURE 3. Search results in databases. RCT: randomized controlled trial "Other diseases" include diabetes mellitus, bariatric surgery, irritable bowel syndrome, colorectal carcinoma, and milk protein allergy, among others, without hepatic outcomes. "Other" includes studies with drugs other than those of interest, in vitro studies, case reports, animal studies, and full articles in a language other than English, French, or Spanish, among others.

TABLE 2. Randomized controlled trials with intervention on the microbiota for liver diseases.

\begin{tabular}{|c|c|c|c|c|c|c|c|}
\hline Author, year & $\mathrm{n}$ & Drug & Placebo & Disease & Outcomes & Result & NCT \\
\hline Bajaj, 2014 & 30 & LGG - 8 weeks & Yes & Cirrhosis - MHE & $\begin{array}{l}\text { Safety, systemic inflammation, } \\
\text { microbiota }\end{array}$ & Positive & Yes \\
\hline Alisi, 2014 & 48 & VSL\#3 - 4 months & Yes & NAFLD pedriatrics & Steatosis (ultrasound) & Positive & Yes \\
\hline Dhiman, 2014 & 130 & VSL\#3 - 6 months & No & Cirrhosis - MHE & OHE & Negative & Yes \\
\hline Nabavi, 2014 & 72 & Yogurt & No & NAFLD & Metabolic syndrome, liver enzymes & Positive & No \\
\hline Sharma, 2014 & 124 & Probiotics & Yes & Cirrhosis - MHE & MHE improvement & Positive & Yes \\
\hline Horvath, 2016 & 80 & VSL\#3 & Yes & Cirrhosis & $\begin{array}{c}\text { Innate immunity, intestinal } \\
\text { permeability, bacterial translocation }\end{array}$ & Positive & Yes \\
\hline Sepideh, 2016 & 42 & Probiotics - 8 weeks & Yes & NAFLD & $\begin{array}{l}\text { Glicemic control and systemic } \\
\text { inflammation }\end{array}$ & Positive & No \\
\hline Famouri, 2017 & 64 & Probiotics - 12 weeks & Yes & NAFLD pedriatrics & Steatosis, liverenzymes & Positive & No \\
\hline Xia, 2018 & 67 & Probiotics & Yes & Cirrhosis - MHE & MHE improvement, microbiota & Positive & No \\
\hline
\end{tabular}

NCT: National Center for Tumor Diseases (NCT) trial registration; LGG: Lactobacillus rhamnosus GG; MHE: minimal hepatic encephalopathy; VSL\#3: Lactobacillus acidophilus, L. plantarum, L. paracasei, L. bulgaricus, Bifidobacterium brevis, B. longum, B. infantis, Streptococcus thermophilus 1x109 CFUNAFLD: non-alcoholic fatty liver disease; OHE: overt hepatic encephalopathy; MHE: minimal hepatic encephalopathy; US: ultrasound. 
(NAFLD and HE), were generally positive but of debatable clinical significance. Reviews and meta-analyses on the subject have been published in recent years ${ }^{(98,127-130)}$, and the conclusion of this review does not differ from that indicated in these other articles: the approach has a solid theoretical framework and seems promising, but it is still premature to recommend its clinical use. Studies with larger samples and longer treatment, that have better-standardized agents in terms of their presentation and number of colonies, and that use objective outcomes, such as liver biopsy, and not substitute outcomes, according to the disease under evaluation, are necessary for a deeper understanding of the usefulness of probiotics in humans.

\section{ROLE OF MICROBIOTA IN GASTROINTESTINAL DISEASES}

\section{Inflammatory bowel disease}

IBD is a set of chronic diseases characterized by a chronic inflammation of the gastrointestinal tract. It includes Crohn's disease and idiopathic ulcerative colitis. The etiology is multifactorial, but it is believed that activation of the immune system against gut microbiota antigens occurs in genetically susceptible individuals ${ }^{(131)}$.

The intestinal microbiome of patients with IBD has a marked dysbiosis, consisting of a general reduction of microbial diversity ${ }^{(132,133)}$, as well as a reduction of essential bacteria for intestinal homeostasis, such as members of the class Clostridia and, in parallel, an increase in potentially pathogenic bacteria, such as adherent-invasive $E$. coli (AIEC) ${ }^{(134)}$. One of the most prominent changes has been the reduction of bacteria of the phylum Firmicutes and, consequently, of Faecalibacterium prausnitzii $i^{(135)}$, in addition to the reduction of other bacteria with anti-inflammatory properties, such as Bifidobacteria ${ }^{(133)}$. Dysbiosis favors the establishment and/ or proliferation of different classes of pathogens in the gut that, through their pathogenicity factors, contribute to the manifestation and/or aggravation of injuries through mechanisms that include increased intestinal permeability, increased exposure to antigens, stimulation of the immune system, and consequently tissue damage.

The composition of the maternal microbiota may influence the gut microbiota and the development of the immune system of the infant. Mothers with IBD and their infants present with altered gut bacterial composition and biodiversity ${ }^{(136)}$, characterized by increased Gammaproteobacteria and decreased Bacteroidetes in mothers and increased Gammaproteobacteria and decreased Bifidobacteria in newborns ${ }^{(136)}$. It is believed that this change may influence the development of the infant's immune system and lead to increased susceptibility to the development of the disease in the future.

The gut microbiota participates in the regulation of several body systems through its metabolites, the SCFAs, especially acetate, propionate, and butyrate ${ }^{(7)}$. These substances are produced in the colon from the fermentation of nondigestible carbohydrates and modulate the systemic immune response, regulating the function of almost every kind of immune cell, altering gene expression, differentiation, chemotaxis, proliferation, and apoptosis ${ }^{(137)}$.

The administration of butyrate or even prebiotics, probiotics, or synbiotics, as well as fecal microbiota transplantation, are promising strategies for the correction of dysbiosis and modulation of the gut microbiota. Despite some positive results, the data are insufficient for the indication of these strategies in the daily management of IBD.

Probiotics can be considered in the maintenance of remission of idiopathic ulcerative colitis, and the E. coli Nissle 1917 or VSL \#3 strain can be considered for the induction of remission in mild to moderate forms of the disease ${ }^{(138)}$. The use of probiotics is not recommended for the induction of remission or maintenance of remission in Crohn's disease ${ }^{(138)}$.

Fecal microbiota transplantation consists of the infusion of a fecal suspension from a healthy individual into the gastrointestinal tract of a sick person. Clinical trials have shown positive results in the induction of clinical and endoscopic remission in patients with active idiopathic ulcerative colitis compared to placebo ${ }^{(139,140)}$, but more consistent studies with a greater number of participants are needed for consolidating the technique. In addition, there are still other questions to be answered, such as what would the ideal donor be like; whether single-donor feces or feces from a donor pool would be best; previous use of antibiotics by the recipient; use of fresh or frozen feces or even lyophilized feces; administration by enteral tube, colonoscopy, retention enema, or capsules; and the periodicity of the procedure.

In summary, IBD patients present changes in the gut microbiota and decreased bacterial diversity, characterizing a state of intestinal dysbiosis. Probiotics may be considered for the induction and maintenance of remission in idiopathic ulcerative colitis, but there is no indication of their use in Crohn's disease. Further studies are needed before fecal microbiota transplantation can be indicated as a treatment for IBD in daily practice.

\section{Antibiotic- and Clostridium difficile - associated diarrhea}

In recent decades, the indiscriminate use of antibiotics has led to significant changes in the gut microbiota: reduction in diversity, loss of homeostasis, and increase in susceptibility to infections, especially Clostridioides difficile infections. It is estimated that 5 to $35 \%$ of patients using antimicrobial agents present with diarrhea as an adverse effect and that $C$. difficile is the culprit in up to $1 / 4$ of these cases ${ }^{(141,142)}$.

C. difficile is a Gram-positive bacillus, anaerobic, with high germination and toxin production potential. It was described in 1935 in newborns and is currently the most common cause of diarrhea in the hospital setting. In recent decades, there has been a significant increase in the number of infected individuals, and in the United States, the estimated prevalence is 500,000 cases/year ${ }^{(143)}$.

In addition to the use of antimicrobials, other risk factors are related to dysbiosis and $C$. difficile infection, such as age over 65 years, prolonged hospitalization, active cancer, IBD, chronic kidney disease, and the use of PPIs. In fact, prior exposure to antibiotics is not identified in up to $40 \%$ of patients ${ }^{(144)}$.

Antibiotic-induced diarrhea has a mild clinical presentation and is directly related to the spectrum of action of the drug. Clindamycin, cephalosporins, and amoxicillin/clavulanate are among the drugs most frequently implicated in this condition. Infection with $C$. difficile may progress to pseudomembranous colitis, toxic megacolon, bowel rupture, and death. The 90-day mortality rate of patients with colitis is $22 \%$, and 29,000 deaths were attributed to the disease in $2014^{(145)}$.

Some pathophysiological mechanisms have been proposed to explain the germination of nonpathogenic bacteria in the colon, including the role of bile acid metabolism. In healthy individuals, colonic bacteria are responsible for the deconjugation and $7 \alpha$-dehydroxylation of primary bile salts (cholic and chenodeoxycholic acid) into secondary salts (lithocholic and deoxycholic acid), which inhibit the dissemination of $C$. difficile strains by direct 
competition. In situations of antibiotic-induced dysbiosis, there is reduced formation of secondary bile acids and consequently greater proliferation and sporulation of $C$. difficile ${ }^{(146)}$.

Experimental studies in mice treated with antibiotics demonstrate a significant reduction in the diversity of the gut microbiota, with an increased population of the phylum Proteobacteria and reduced Firmicutes and Bacteroidetes. The time to reestablish the bacterial flora in these animals ranges from 2 weeks to 6 months ${ }^{(146)}$.

In addition, detailed analysis of the phenotype and of the function of the microbiota through the metabolome points to a metabolic dysregulation of carbohydrates and amino acids. Antibiotic-induced dysbiosis reduces the production of SCFAs and increases the likelihood of $C$. difficile colonization ${ }^{(146)}$.

The role of the microbiota in $C$. difficile infection is well established, and one of the practical implications is the indication of fecal transplantation in the treatment of recurrent cases. The use of probiotics also seems to prevent the occurrence of antibioticassociated diarrhea by reestablishing the intestinal permeability and microenvironment ${ }^{(147,148)}$.

Some meta-analyses suggest a benefit to using Saccharomyces boulardii, Lactobacillus, Bifidobacterium, and Streptococcus strains. The number needed to treat to prevent one episode of antibioticassociated diarrhea was $12-40$ and to prevent one episode of $C$. difficile-associated diarrhea was $10-67^{(149)}$. The most recent Cochrane systematic review included approximately 8,500 cases and showed a moderate benefit in the prevention of $C$. difficile diarrhea, especially in low- to intermediate-risk patients. The main limitations of this meta-analysis were the heterogeneity between studies and the use of different strains, doses or administration times ${ }^{(150)}$.

Future studies are needed to define the most suitable strain for each patient, the amount of bacteria, the duration of use, and the side effects of the probiotic.

\section{Irritable bowel syndrome and functional constipation}

Functional diseases are quite common and are characterized by a complex physiopathology, which includes, among others, the presence of increased intestinal permeability, intestinal inflammatory infiltrate, altered expression of several receptors, visceral hypersensitivity, and, especially, anomalous functioning of the brain-gut axis and dysbiosis. This state, although quite difficult to understand, can be defined by an imbalance between the good and bad bacteria that colonize our digestive tract, a lack of microbiota stability, and, especially, a decrease in the gut bacterial diversity. The differences observed when comparing healthy individuals with other patients with functional diseases seem to be clear. Among these conditions, irritable bowel syndrome (IBS) is perhaps one of the most studied functional diseases.

In IBS, studies have shown a clear difference in microbiota when comparing patients with healthy controls. The analysis of the microbiota may show an increase in certain microorganisms (such as Lactobacillus, Veillonella, and Enterobacteriaceae) or a decrease in others (such as Bifidobacterium and Clostridium). It is clear, however, that in IBS, the microbiota differs in terms of both number and diversity of microorganisms. What still needs to be established is whether this pattern of dysbiosis found in IBS is specific to this condition ${ }^{(151)}$. A logical approach to the treatment of functional syndromes would be to correct this microbiota imbalance. This can be achieved in various ways, for example, by dietary changes; physical exercise; use of drugs that somehow alter intestinal motility, sensitivity, or immunity; or through the use of mechanisms that can directly modify or rebalance the microbiota, such as antibiotics, but especially probiotics, prebiotics, and possibly even fecal transplantation, although the safety of this last approach is still debatable, which limits the application of this treatment, for this indication, to research protocols ${ }^{(34,152)}$.

Supplementation with probiotics can restore eubiosis, modifying metabolic, immune, motor, and brain-gut axis functions. Several meta-analyses, including studies on multiple and single strains, yielded highly variable results, dependent not only on the genus and species used but also on the strains involved. There was also a large discrepancy in the number of patients studied, length of treatment, and type of association of strains. Because the probiotic response is strain-specific, meta-analyses encompassing different strains and associations should be interpreted with caution. In fact, metaanalyses with one strain or with the same combination of strains would be necessary to arrive at more reliable conclusions ${ }^{(153-160)}$.

In this clinical situation, we are still not able to recommend a specific strain that has sufficient support to be used for this purpose, especially with regard to the different clinical presentations of this syndrome, i.e., with a predominance of diarrhea, constipation, or a mix. The major difference between IBS and other functional diseases, such as diarrhea and constipation, is the presence of abdominal pain, such that the simple correction of bowel habits and fecal consistency is not sufficient, and there is also a need for control of abdominal pain, so that the patient actually experiences improved quality of life. This hinders the ability to use only probiotics alone to manage this syndrome, though probiotic supplementation may be used as adjuvant therapy ${ }^{(159,161-163)}$.

The strains recommended by the World Gastroenterology Organization for use in IBD are the following ${ }^{(164)}$ : Bifidobacterium bifidum MIMBb75, Lactobacillus plantarum 299v (DSM 9843), E. coli DSM17252, L. rhamnosus NCIMB 30174, L. plantarum NCIMB 30173, L. acidophilus NCIMB 30175, Enterococcus faecium NCIMB 30176, Bacillus coagulans + fructooligosaccharides, $L$. animalis subsp. lactis BB-12 ${ }^{\circledR}$, L. acidophilus LA- $5^{\circledR}$, L. delbrueckii subsp. bulgaricus LBY-27, Streptococcus thermophilus STY-31, and Saccharomyces boulardii CNCM I-745. More recent studies have found that for the control of general symptoms associated with IBS, bifidobacteria seem to lead to better relief of symptoms; however, lactobacilli seem to perform better in the treatment of distension and bloating ${ }^{(165,166)}$. Because IBS is a chronic condition, probiotic supplementation should also be carried out for a long time.

In the case of functional constipation, simple correction of bowel habits and fecal consistency brings great improvement to the quality of life of patients. Here, again, many studies have been conducted with a wide variety of strains and combinations. There is good evidence of different microbiota patterns between constipated and nonconstipated patients. Probiotics can act directly in the bowel transit, stimulating the release of several neurotransmitters locally or modulating the action of the brain-gut axis. The production of SCFAs via fermentation of nondigestible carbohydrates also seems to be important in the beneficial effect of probiotic supplementation $^{(167-170)}$.

The World Gastroenterology Organization recommends the following strains to treat functional constipation ${ }^{(164)}$ : the combination of the strains Bifidobacterium bifidum (KCTC 12199BP), B. lactis (KCTC 11904BP), B. longum (KCTC 12200BP), L. acidophilus (KCTC 11906BP), L. rhamnosus (KCTC 12202BP), and Streptococcus thermophilus (KCTC 11870BP) and the use of L. reuteri DSM 17938 alone. 


\section{Acute infectious diarrhea}

Diarrhea is a common clinical manifestation of several diseases and may be defined as the presence of three or more bowel movements per day, usually of loose stools, or by the passing of more than $200 \mathrm{~g}$ of stool weight per day. However, changes in the normal bowel rhythm, both in consistency and in the number of bowel movements, tend to be more important than the specific appearance or number of bowel movements. During the first months of life, children, especially those fed breast milk, may normally have approximately 8 to 10 bowel movements per day with semiliquid stools, without it being considered diarrhea ${ }^{(171,172)}$.

Acute diarrhea (AD) lasts less than two weeks, usually presenting with a self-limited course. Most of the time, it is resolved in approximately 7 days, with progressively fewer cases showing improvement in 14, 21, or 28 days. The term "persistent diarrhea" may also be reserved for cases lasting more than 14 days. This limit of 14 days may seem arbitrary, but it is supported by the fact that mortality increases considerably after this period. Persistent diarrhea is more commonly found in children younger than 5 years old, excluding organic diseases such as celiac disease, tropical sprue, cystic fibrosis, Crohn's disease, idiopathic ulcerative colitis, etc. Diarrhea is considered chronic when lasting more than 4 weeks ${ }^{(173)}$.

Diarrhea is considered the second-leading cause of mortality worldwide and the leading cause of death in the pediatric population; its rates increase with the worsening of the sanitary conditions. Its frequency is perhaps underestimated because most of the cases have spontaneous resolution and do not require medical care. It is estimated that children under 4 years of age worldwide have 3.2 episodes of diarrhea per year, leading to 3.8 deaths per thousand children in this age group ${ }^{(174)}$. We have seen a decrease in mortality rates in recent years, especially when studying children younger than 1 year, most likely due to the increasing use of oral hydration solutions, along with breastfeeding and improved sanitary conditions ${ }^{(171)}$. In adults, it is estimated that $20 \%$ of the population has at least one episode of diarrhea per year, and an infectious agent is recognized in $30 \%-40 \%$ of cases, with a predominance of viral causes. There are several risk factors for the onset of diarrhea: recent trips to areas with poor basic sanitation, campers (sources of contaminated water), intake of suspect foods (seafood, savory snacks, mayonnaise, restaurants, banquets, etc.), at-risk groups (homosexuals, sex workers, intravenous drug users, etc.), recent use of antibiotics, and hypochlorhydria ${ }^{(175)}$.

The occurrence of diarrhea reflects a change in the intestinal barrier in our body, which, when healthy, through the adequate production of mucus, IgA, and defensins as well as the activity of tight junctions, is able to prevent the resident harmful microbiota from causing disease. In cases of dysbiosis (imbalance between the symbiont and pathobiont microbiota), there is loss of this protective barrier, with decreased secretion of mucus, $\operatorname{IgA}$, and defensins, in addition to loss of efficacy of tight junctions, increasing the intestinal permeability and allowing pathogenic agents to enter the mucosa, thus triggering an inflammatory process that culminates with increased intestinal secretion and motility, leading to diarrhea ${ }^{(176)}$.

The treatment of $\mathrm{AD}$ begins with its prevention, which in turn involves improved sanitation conditions, basic hygiene guidelines, especially for professionals dealing with food handling, and, vaccination against rotavirus, still a very important cause of $\mathrm{AD}$ in both children and adults. Another prophylactic approach would be the use of probiotics in high-risk populations such as institutionalized children or people traveling to areas with poor sanitation conditions. The evidence is less robust for this particular indication, although there are studies that show very promising results(177-179). After the onset of diarrhea, its clinical approach should target the decrease in the number of bowel movements, their volume, and the treatment of associated symptoms such as fever, nausea, vomiting, and abdominal cramps, in addition to the correction of fluid and electrolyte disorders, especially focusing on oral or parenteral hydration depending on the situation ${ }^{(178,180-184)}$.

Supplementation with probiotics in AD makes perfect sense because intestinal infections are considered classic examples of microbiota imbalance. These living organisms play multiple roles in the treatment of acute gastroenterocolitis. They displace pathogens from intestinal receptors, compete for nutrients in the intestinal lumen, promote bacterial fermentation, and release SCFAs (butyrate, lactate, propionate), which in turn decrease the luminal $\mathrm{pH}$, preventing the proliferation of other aggressive strains. Butyrate also participates in the nourishment of colonocytes and significantly increases the absorption of water and electrolytes. Probiotics are still important in this clinical situation because they exert immunomodulatory effects ${ }^{(185,186)}$.

In viral diarrhea, it is common to have superficial mucosal damage, promoting loss of disaccharidases, especially lactase, causing these patients to develop secondary intolerance to lactose, hindering the control of AD. Lactobacilli may reduce this intolerance by producing beta-galactosidase (lactase) ${ }^{(187)}$. Supplementation with probiotics has been shown, on average, to reduce the duration of diarrhea by approximately 24 hours. In children it is especially associated with decreased length of fever and of hospital stay. The greatest evidence of its benefit is in the pediatric population, which is also the population most vulnerable to infectious diarrhea and is therefore much more studied than adults. The strains with most evidence for this purpose in this population are L. rhamnosus GG, Saccharomyces boulardii, and L. reuteri DSM17938(182,188-198). In adults, studies are scarcer, and the World Health Organization recommends the following strains for the treatment of $\mathrm{AD}$ in adults: L. paracasei B 21060 or L. rhamnosus GG $10^{9}$ UFC twice a day, and Saccharomyces boulardii CNCM I-745, S. cerevisiae strain $10^{9}$ CFU 250-mg capsule also twice a day ${ }^{(164)}$. In a recent guideline, the Infectious Diseases Society of America recommends the use of probiotics in adults to reduce the severity of symptoms and the duration of acute infectious diarrhea ${ }^{(199)}$. More recently, the American College of Gastroenterology found evidence for the use of two strains in mild to moderate AD, Saccharomyces boulardii and Lactobacillus SF68 ${ }^{(149)}$

\section{Treatment of Helicobacter pylori}

Helicobacter pylori $(\mathrm{Hp})$ is one of the most prevalent infections worldwide, infecting practically half the population of our planet. In Brazil, $H p$ has an estimated prevalence of $60 \%-70 \%$ of the entire population, with areas of higher or lower prevalence depending on basic sanitation conditions in the region. $H p$ has its eradication recommended in a number of clinical situations, and its importance is such that it has motivated the reaching of various consensuses to standardize its treatment and monitor its progression. The treatment involves the use of different antibiotic combinations, always combined with a PPI or, more recently in Japan, combined with a potassium-competitive inhibitor (vonoprazan) (200-203).

The use of antibiotics is known to be associated with a great imbalance of the gut microbiota, which may have several consequences for our health. Recently, we have observed a progressive 
increase in bacterial resistance, including $H p$, to a wide range of antibiotics, making it necessary to use longer regimens and eventually use multiple regimens for the lack of response to the initial regimen $^{(203)}$.

Probiotic supplementation together with an antibiotic regimen during $\mathrm{Hp}$ eradication makes sense for minimizing the deleterious effects of antibiotic therapy, limiting adverse effects, improving adherence and making the patient more comfortable. Another function would be a direct effect on $H p$ with the goal of increasing eradication rates. Adherence is an important factor that correlates directly with treatment success ${ }^{(200,203)}$.

Probiotics can improve $H p$ eradication through several mechanisms: direct bactericidal effect acting on bacterial urease via bacteriocin production, immunomodulatory effect via action on PRRs, and acting as scavengers of free radicals released in the stomach by $\mathrm{Hp}$. Some studies have shown an additive effect of probiotics in the prevention of gastric colonization by $\mathrm{Hp}^{(200)}$. Some probiotic strains of lactobacilli, bifidobacteria, and Saccharomyces proved to be effective in reducing $H p$ activity in vitro. Again, these effects are strain specific and should not be generalized to all probiotics. In general, the results are quite promising, showing that certain strains can reduce the adverse effects of antibiotic treatment and eventually increase eradication rates. The time when probiotics should be started and for how long is also under debate. Probiotic supplementation starting approximately 7 days before and going until 7 days after the end of antibiotics seems to be the most beneficial approach, but there is still no consensus on this issue. The last Brazilian consensus on $H p$ still does not recommend the use of probiotics for the aforementioned purposes, as well-conducted studies are needed with specific strains for this purpose, a conclusion that corroborates other international consensuses. A recent meta-analysis on the subject showed that probiotic supplementation may reduce the adverse effects of eradication therapy ${ }^{(200,204,205)}$.

The World Gastroenterology Organization cites some probiotic strains as promising for use in the treatment of $H p:^{(164)} \mathrm{L}$. rhamnosus GG, Bifidobacterium animalis subsp. lactis (DSM15954) + L. rhamnosus GG, L. reuteri DSM 17938, L. acidophilus $+L$. bulgaricus + Bifidobacterium bifidum + Streptococcus thermophilus + galactooligosaccharides, L. acidophilus, Streptococcus faecalis, and Bacillus subtilis. The American College of Gastroenterology cites the following probiotics reported in well-conducted studies and with some evidence to be used for this purpose ${ }^{(149)}$ : Lactobacillus (acidophilus, bulgaricus, casei, delbrueckii, gasseri, paracasei, plantarum, reuteri, rhamnosus GG), Bifidobacteria (B-12, bifidum, breve, clausii, DN-173, infantis, lactis, longum), Streptococcus (faecium, thermophiles), and Clostridium butyricum.

\section{ROLE OF MICROBIOTA: WAY BEYOND THE DIGESTIVE TRACT}

\section{Prevention and treatment of cancer}

Cancer is one of the leading causes of death worldwide. It is a multifactorial disease that involves genetic and environmental factors. The immunological condition of the individual has a considerable influence on the development of this disease, and the human microbiota, through its interaction with the immune system and importance in homeostasis, participates in this disease process, which makes the microbiota the target of research on cancer prevention and treatment ${ }^{(206,207)}$.

The immunomodulatory action of the microbiota is based on the interaction of intestinal bacteria and their metabolites with the immune system and epithelial cells (see above). Probiotics can increase or suppress the production of inflammatory cytokines and modulate the secretion of prostaglandins. Inflammation in turn can lead to mutations and instabilities in the genome in regions linked to the proliferation of cancer cells and to the production of tissue-remodeling enzymes, angiogenic factors, or growth factors ${ }^{(208,209)}$.

The specific mechanisms of antitumor activity of probiotics are not yet fully established, but several known pathways support their utility. An example is the importance of the microbiota in maintaining an adequate $\mathrm{pH}$, which contrasts the direct cytotoxic effect caused by the decrease in $\mathrm{pH}$ secondary to an excess of bile salts. Furthermore, some putrefactive bacteria, such as E. coli and Clostridium perfringens, are involved in the production of carcinogens through the use of enzymes such as glucuronidase, azoreductase, and nitroreductase. The use of probiotics and prebiotics could increase the number of other bacterial species, competitively reducing the putrefactive bacteria and their consequent action on carcinogenesis ${ }^{(208-210)}$. Other mechanisms associated with the preventive action of the microbiota include increased carcinogen degradation, regulated, for example, by Lactobacillus and Bifidobacillus, increased SCFA production, and immunomodulation. In vitro studies postulate that SCFAs have the ability to inhibit the growth of cancer cells. For example, butyrate is an SCFA directly acquired through the diet or through the metabolism and fermentation of other substances, such as fibers. Conditions such as colitis or cancer, which affect the metabolism of butyrate, lead to its intracellular accumulation, which is related to cell death. In this sense, its ability to inhibit cell proliferation and promote the differentiation and apoptosis of cells, including neoplastic cells, has been demonstrated. SCFAs interact with the immune system and influence the intestinal production of hormones and lipogenesis. These actions culminate in their crucial role of maintaining intestinal integrity and explain the strong correlation between colorectal cancer and decreased levels of these substances ${ }^{(206,207,209)}$.

Given that the prevalence of certain bacteria is directly related to eating habits, dietary changes could influence cancer prevention and therapy. Intermittent fasting, for example, can positively influence the microbiota, by increasing the genus Firmicutes, which has been linked to higher SCFA production. As stated, these elements are linked to the prevention and treatment of cancer, with evidence of comparative reductions in tumor mass in rat models. The Mediterranean diet, characterized by low intake of saturated fatty acids and high intake of mono- or polyunsaturated fatty acids, as well as diets with lower carbohydrate content, are other diets associated with lower inflammation and higher SCFA production ${ }^{(207,209,211)}$.

Another feature of the gastrointestinal tract microbiota is its ability to modulate the efficacy of chemotherapy drugs. Certain bacterial strains, as shown in studies in experimental rat models, are capable of acting synergistically with chemotherapeutic agents. For example, in the case of cyclophosphamide, the presence of a specific group of Gram-positive bacteria (segmented filamentous bacteria, L. johnsonii, L. murinus, and Enterococcus hirae) is essential to mediate the accumulation of T-helper (Th) 17 lymphocytes and the Th1 response, which are important mechanisms in the action of this drug. The pharmacokinetics of other chemotherapeutic agents, such as 5-fluoroacyl, irinotecan, oxaliplatin, gemcitabine, and methotrexate, have also been associated with the microbiota in in vitro studies ${ }^{(206,208,209)}$. 
The gut microbiota can be manipulated for optimization of anticancer treatment by several methods. The most studied are the use of probiotics, dietary changes, and fecal transplantation. The main outcome of microbiota manipulation is the reduction of the toxicity of chemotherapeutic drugs, but further studies are needed to demonstrate a real increase in the efficacy of antineoplastic $\operatorname{drugs}^{(207,208,210,211)}$.

With regard to the prevention of complications from the use of chemotherapeutic agents, several events can be avoided by manipulating the microbiota. Lactobacillus supplementation, which has a reasonable cost and dosage, may reduce the frequency of chemotherapy-induced diarrhea and reduce episodes of abdominal pain and symptoms of acute mucositis secondary to radiotherapy and cytotoxic chemotherapy. Modulating the gut microbiota can prevent the rupture of the epithelial barrier, with beneficial effects on tumor cachexia, antineoplastic therapy-related infections, and depression in patients receiving a combination of probiotics ${ }^{(207,209,210)}$.

Thus, we can conclude that the microbiota plays a key role in host homeostasis and that changes in the microbiota may be associated with diseases such as cancer or worse therapeutic responses, such as to the use of chemotherapeutic agents. Understanding the factors that modify the microbiota may be useful for improving preventive measures for these pathologies and for the emergence of new treatment options in the clinical management of these diseases.

\section{Gynecological diseases, atopy, depression, anxiety, and autism}

Certain probiotic strains have potential in preventing and treating various extraintestinal disorders. In gynecology, there are several studies that address the role of probiotics mainly in the treatment of vaginosis and vaginal candidiasis and even in the prevention of urinary tract infections ${ }^{(212,213)}$.

In neurology and psychiatry, there is growing evidence of a relationship between the gut microbiota and diseases such as depression, anxiety, and even autism. Probiotic strains are being developed and specifically studied for this purpose, and they even get a special name: psychobiotics ${ }^{(3,214-217)}$.

In allergic diseases, there has also been a significant expansion of the knowledge on this topic, including discussion on the supplementation of certain strains during pregnancy to prevent the development of atopy in children, especially in the children of atopic parents ${ }^{(218-221)}$

We will need a larger number of well-conducted prospective, randomized, placebo-controlled studies in these three areas so that we can identify the exact strains to be supplemented in different clinical situations.

\section{Critical analysis of the use of prebiotics, postbiotics and synbiotics in digestive tract diseases}

As discussed above, the microbiota plays an important role in health maintenance in all senses, and its manipulation is possible through several mechanisms, one of which is the use of probiotics. It must be mentioned again that the action of these good bacteria depends on a number of factors, including the strain used, its quantity, the matrix in which it is provided, temperature, drugs taken in combination with it, underlying disease, the TLRs involved in its effects, age, etc. The response is strain specific and is not necessarily additive with the combination of more strains or prebiotics. Strains given in combination need also to be studied together to confirm their probiotic effect ${ }^{(49)}$. To arrive at a probiotic strain for clinical use, numerous initial studies are necessary to characterize it, analyze its behavior in vitro, and test it in vivo in animals and, ultimately, in humans. These studies are essential to confirm its clinical effect and especially its safety, especially when provided to children, pregnant women, and immunosuppressed individuals ${ }^{(49)}$.

For a probiotic to act as such, it must be provided in adequate amounts, must resist the passage through the stomach $(\mathrm{HCl}$ and pepsin) and duodenum (bile salts and pancreatic enzymes), must be preserved and transported under ideal temperature and pressure conditions, and, obviously, must have confirmed beneficial action and, especially, safety ${ }^{(1,49,222)}$. The probiotics recorded in Brazil are proven safe. However, they should not be supplemented in patients with severe immunodeficiency or with a serious health condition, such as individuals in shock who are maintained with vasoactive drugs. ${ }^{49,210}$ It is important that we know the immunomodulatory effect of each strain because it is possible to promote a certain type of immune response that is undesirable in a given clinical situation. Probiotics that stimulate Th2 responses may aggravate Th2-dependent diseases. Another concern with its safety would be the eventual transmission of antibiotic resistance of probiotic strains to commensal bacteria in our body. Although this is possible, this phenomenon has not been observed among the probiotics available in Brazil ${ }^{(49,210)}$.

Ideally, we would be able to provide a certain number of bacteria or fungi that could definitively colonize our gut, but this is not possible. The effect of probiotics occurs when they are supplemented, such that for chronic diseases, their supplementation must be chronic, and for acute affections, they should be supplemented for a limited time ${ }^{(1,31,222)}$. For the vast majority of clinical situations in gastroenterology, we still cannot indicate a specific strain. However, for conditions such as AD, IBS, functional constipation, and diarrhea, including antibiotic-associated diarrhea, there is strong evidence of the beneficial action of probiotics. The most studied strains in each of these situations are mentioned in the text above $\mathrm{e}^{(149)}$. Other promising indications, such as in the treatment of psychiatric diseases, genitourinary diseases, allergic and rheumatic diseases, and even in the prevention of certain types of cancers, were not addressed in this text more in depth, but the role of probiotics in these clinical situations is the same as described for gastrointestinal diseases.

Our position is to provide guidance to the clinician about the most studied strains in each clinical situation, with the caveat that the evidence is not always robust for the strains mentioned. We also emphasize the notion that the probiotic effect is strain-specific and that it is possible for different strains to interact when taken together. The manipulation of probiotics, in our opinion, does not provide a guarantee as to the origin of the strain used and, therefore, cannot be recommended at this time. In addition, combination of strains not previously studied may result in inferior results. It is very important that universities and research institutes grow the number of studies in this area so that we may establish more precise indications for probiotic supplementation and identify strains specific to each clinical indication.

\section{ACKNOWLEDGEMENTS}

The authors would like to thank Drs. Schlioma Zaterka, Maria do Carmo F Passos, Esther Sabino, Flair José Carrilho, Isaac Altikes, Renata de Mello Perez, Edna Strauss, Maria Lucia 
Gomes Ferraz, Edison Roberto Parise, Alexandre de Souza Carlos, Aparecida Paceta, Sabrina Rodrigues de Figueiredo, Thaís Cabral de Melo Viana for the contribution to the manuscript as well as to the Brazilian Society of Hepatology (SBH), Brazilian Nucleus for the Study of Helicobacter Pylori and Microbiota (NBEHPM), and Brazilian Federation of Gastroenterology (FBG).

\section{Authors' contribution}

Barbuti RC, Schiavon LL, Oliveira CPMS, Alvares-da-Silva MR, Sassaki LY, Farias AQ, Barros LL, Barreto BP, Albuquerque GBML, Alves AM, Navarro-Rodriguez T, Bittencourt PL: wrote the paper. Barbuti RC, Schiavon LL, Passos MCF: critically reviewed the manuscript. Bittencourt PL and Barbuti RC: organized the joint meeting on gut microbiota and the use of prebiotics, probiotics, and synbiotics in gastrointestinal and liver diseases.

\section{Orcid}

Ricardo Correa Barbuti: 0000-0002-1910-119X.

Leonardo Lucca Schiavon: 0000-0003-4340-6820.

Cláudia PMS Oliveira: 0000-0002-2848-417X.

Mário Reis Alvares-da-Silva: 0000-0002-5001-246X.

Lígia Yukie Sassaki: 0000-0002-7319-8906.

Maria do Carmo F Passos: 0000-0002-5247-9477.

Alberto Queiroz Farias: 0000-0002-5572-663X.

Luisa Leite Barros: 0000-0002-7782-2825.

Bruno Paes Barreto: 0000-0001-6892-0004.

Gisela Bandeira de Melo Lins de Albuquerque: 0000-00023882-4895.

Amanda Mandarino Alves: 0000-0001-5790-5554.

Tomás Navarro-Rodriguez: 0000-0002-3458-699X.

Paulo Lisboa Bittencourt: 0000-0003-0883-4870.

Barbuti RC, Schiavon LL, Oliveira CP, Alvares-da-Silva MR, Sassaki LY, Passos MCF, Farias AQ, Barros LL, Barreto BP, Albuquerque GBML, Alves AM, Navarro-Rodriguez T, Bittencourt PL. Microbiota intestinal, prebióticos, probióticos e simbióticos em doenças gastrointestinais e hepáticas: procedimentos de reunião conjunta da Sociedade Brasileira de Hepatologia (SBH), Núcleo Brasileiro de Estudos do Helicobacter pylori e Microbiota (NBEHPM) e Federação Brasileira de Gastroenterologia (FBG). Arq Gastroenterol. 2020;57(4):381-98.

RESUMO - Nos últimos anos, um volume crescente de evidências indica que os microrganismos estão envolvidos na manutenção da saúde humana e também estão relacionados a várias doenças, tanto intestinais quanto extraintestinais. Alterações na microbiota intestinal parecem ser um elemento chave na patogênese de doenças hepáticas e gastrointestinais, incluindo doença hepática gordurosa não-alcoólica, doença hepática alcoólica, cirrose hepática, doenças inflamatórias intestinais, síndrome do intestino irritável e diarreia associada ao Clostridium difficile. Em 2019, a Sociedade Brasileira de Hepatologia (SBH) em colaboração com o Núcleo Brasileiro para Estudo do Helicobacter pylori e Microbiota (NBEHPM) e a Federação Brasileira de Gastroenterologia (FBG) realizaram um encontro exclusivamente voltado para a discussão sobre microbiota e uso de prebióticos, probióticos e simbióticos em doenças hepáticas e gastrointestinais. Este texto resume os principais pontos discutidos durante o evento, e tem a intenção de fornecer informações práticas sobre o assunto, abordando as descobertas mais recentes e indicando áreas para estudos futuros.

DESCRITORES - Microbioma gastrointestinal. Prebióticos. Probióticos. Simbióticos. Gastroenteropatias. Hepatopatias. Guias de prática clínica como assunto.

\section{REFERENCES}

1. Davenport ER, Sanders JG, Song SJ, Amato KR, Clark AG, Knight R. The human microbiome in evolution. BMC Biol. 2017;15(1):127.

2. Akagawa S, Tsuji S, Onuma C, Akagawa Y, Yamaguchi T, Yamagishi M, et al. Effect of Delivery Mode and Nutrition on Gut Microbiota in Neonates. Ann Nutr Metab. 2019;74(2):132-9.

3. Dinan TG, Stanton C, Cryan JF. Psychobiotics: a novel class of psychotropic Biol Psychiatry. 2013;74(10):720-6

4. Vandenplas Y, Huys G, Daube G. Probiotics: an update. J Pediatr (Rio J) 2015;91(1):6-21

5. Bode L, Jantscher-Krenn E. Structure-function relationships of human milk oligosaccharides. Adv Nutr. 2012;3(3):383S-91S

6. Bode L. Human milk oligosaccharides: prebiotics and beyond. Nutr Rev. 2009;67 Suppl 2:S183-91.

7. Jantscher-Krenn E, Bode L. Human milk oligosaccharides and their potential benefits for the breast-fed neonate. Minerva Pediatr. 2012;64(1):83-99

8. Bode L. The functional biology of human milk oligosaccharides. Early Hum Dev. 2015;91(11):619-22.

9. Mohajeri MH, Brummer RJM, Rastall RA, Weersma RK, Harmsen HJM, Faas $\mathrm{M}$, et al. The role of the microbiome for human health: from basic science to clinical applications. Eur J Nutr. 2018;57(Suppl 1):1-14.

10. Butel MJ. Probiotics, gut microbiota and health. Med Mal Infect. 2014;44(1):1-8.

11. Butel MJ, Waligora-Dupriet AJ, Wydau-Dematteis S. The developing gut microbiota and its consequences for health. J Dev Orig Health Dis. 2018:1-8.

12. Schloissnig S, Arumugam M, Sunagawa S, Mitreva M, Tap J, Zhu A, et al. Genomic variation landscape of the human gut microbiome. Nature. 2013;493(7430):45-50

13. Wammes LJ, Mpairwe H, Elliott AM, Yazdanbakhsh M. Helminth therapy or elimination: epidemiological, immunological, and clinical considerations. Lancet Infect Dis. 2014;14(11):1150-62.
14. Virgin HW. The virome in mammalian physiology and disease. Cell 2014;157(1):142-50

15. Consortium HMP. Structure, function and diversity of the healthy human microbiome. Nature. 2012;486(7402):207-14

16. O'Hara AM, Shanahan F. The gut flora as a forgotten organ. EMBO Rep 2006;7(7):688-93.

17. Dobson A, Cotter PD, Ross RP, Hill C. Bacteriocin production: a probiotic trait? Appl Environ Microbiol. 2012;78(1):1-6.

18. Hammami R, Fernandez B, Lacroix C, Fliss I. Anti-infective properties of bacteriocins: an update. Cell Mol Life Sci. 2013;70(16):2947-67.

19. Brüssow H, Parkinson SJ. You are what you eat. Nat Biotechnol. 2014;32(3):243-5.

20. Indira M, Venkateswarulu TC, Abraham Peele K, Nazneen Bobby M, Krupanidhi $\mathrm{S}$. Bioactive molecules of probiotic bacteria and their mechanism of action: a review. 3 Biotech. 2019;9(8):306.

21. Oak SJ, Jha R. The effects of probiotics in lactose intolerance: A systematic review. Crit Rev Food Sci Nutr. 2018:1-9.

22. Willing BP, Russell SL, Finlay BB. Shifting the balance: antibiotic effects on host-microbiota mutualism. Nat Rev Microbiol. 2011;9(4):233-43.

23. Piche T. Tight junctions and IBS--the link between epithelial permeability, low-grade inflammation, and symptom generation? Neurogastroenterol Motil 2014;26(3):296-302.

24. Bercik P, Collins SM, Verdu EF. Microbes and the gut-brain axis. Neurogastroenterol Motil. 2012;24(5):405-13

25. Khlevner J, Park Y, Margolis KG. Brain-Gut Axis: Clinical Implications. Gastroenterol Clin North Am. 2018;47(4):727-39.

26. Sharon G, Sampson TR, Geschwind DH, Mazmanian SK. The Central Nervous System and the Gut Microbiome. Cell. 2016;167(4):915-32.

27. Sampson TR, Mazmanian SK. Control of brain development, function, and behavior by the microbiome. Cell Host Microbe. 2015;17(5):565-76. 
28. Clarke G, Stilling RM, Kennedy PJ, Stanton C, Cryan JF, Dinan TG. Minireview: gut microbiota: the neglected endocrine organ. Mol Endocrinol. 2014;28(8):1221-38.

29. Fukui H, Xu X, Miwa H. Role of Gut Microbiota-Gut Hormone Axis in the Pathophysiology of Functional Gastrointestinal Disorders. J Neurogastroenterol Motil. 2018;24(3):367-86

30. Dongarrà ML, Rizzello V, Muccio L, Fries W, Cascio A, Bonaccorsi I, et al. Mucosal immunology and probiotics. Curr Allergy Asthma Rep. 2013;13(1):19-26.

31. Yousefi B, Eslami M, Ghasemian A, Kokhaei P, Salek Farrokhi A, Darabi N Probiotics importance and their immunomodulatory properties. J Cell Physiol. 2019;234(6):8008-18

32. Peterson CT, Sharma V, Elmén L, Peterson SN. Immune homeostasis, dysbiosis and therapeutic modulation of the gut microbiota. Clin Exp Immunol 2015;179(3):363-77.

33. Kolb R, Sutterwala FS, Zhang W. Obesity and cancer: inflammation bridges the two. Curr Opin Pharmacol. 2016;29:77-89.

34. Vaiserman AM, Koliada AK, Marotta F. Gut microbiota: A player in aging and a target for anti-aging intervention. Ageing Res Rev. 2017;35:36-45.

35. Anderson JW, Baird P, Davis RH, Ferreri S, Knudtson M, Koraym A, et al. Health benefits of dietary fiber. Nutr Rev. 2009;67(4):188-205.

36. Leonel AJ, Alvarez-Leite JI. Butyrate: implications for intestinal function. Curr Opin Clin Nutr Metab Care. 2012;15(5):474-9.

37. Saad S. Probióticos and prebióticos: o estado da arte. J Pharm Sci. 2006; 42(1):1-16.

38. Saad N, Delattre C, Urdaci M, Schmitter J, Bressollier P. An overview of the las advances in probiotic and prebiotic field. LWT-Food Science and Technology. 2013;50(1):1-16.

39. Triantafyllou K, Chang C, Pimentel M. Methanogens, methane and gastrointestinal motility. J Neurogastroenterol Motil. 2014;20(1):31-40.

40. Juhas M. Horizontal gene transfer in human pathogens. Crit Rev Microbiol. 2015;41(1):101-8

41. David LA, Maurice CF, Carmody RN, Gootenberg DB, Button JE, Wolfe BE, et al. Diet rapidly and reproducibly alters the human gut microbiome. Nature. 2014;505(7484):559-63.

42. Bilski J, Mazur-Bialy A, Brzozowski B, Magierowski M, Zahradnik-Bilska J, Wójcik D, et al. Can exercise affect the course of inflammatory bowel disease? Experimental and clinical evidence. Pharmacol Rep. 2016;68(4):827-36.

43. O'Sullivan O, Cronin O, Clarke SF, Murphy EF, Molloy MG, Shanahan F, et al. Exercise and the microbiota. Gut Microbes. 2015;6(2):131-6.

44. Cook MD, Allen JM, Pence BD, Wallig MA, Gaskins HR, White BA, et al Exercise and gut immune function: evidence of alterations in colon immune cell homeostasis and microbiome characteristics with exercise training. Immunol Cell Biol. 2016;94(2):158-63

45. Ramai D, Zakhia K, Ofosu A, Ofori E, Reddy M. Fecal microbiota transplantation: donor relation, fresh or frozen, delivery methods, cost-effectiveness. Ann Gastroenterol. 2019;32(1):30-8

46. Maier L, Pruteanu M, Kuhn M, Zeller G, Telzerow A, Anderson EE, et al. Extensive impact of non-antibiotic drugs on human gut bacteria. Nature. 2018;555(7698):623-8

47. Blaser MJ. Antibiotic use and its consequences for the normal microbiome Science. 2016;352(6285):544-5.

48. Cox LM, Blaser MJ. Antibiotics in early life and obesity. Nat Rev Endocrinol. 2015;11(3):182-90.

49. Sanders ME, Klaenhammer TR, Ouwehand AC, Pot B, Johansen E, Heimbach JT, et al. Effects of genetic, processing, or product formulation changes on efficacy and safety of probiotics. Ann N Y Acad Sci. 2014;1309(1):1-18.

50. Rodriguez J. Probióticos: del laboratorio al consumidor. Nutr Hosp. 2015;31(Supl. 1):33-47

51. Petschow B, Doré J, Hibberd P, Dinan T, Reid G, Blaser M, et al. Probiotics, prebiotics, and the host microbiome: the science of translation. Ann N Y Acad Sci. 2013;1306:1-17.

52. Fijan S. Microorganisms with claimed probiotic properties: an overview of recent literature. Int J Environ Res Public Health. 2014;11(5):4745-67.

53. Platts-Mills TA. The allergy epidemics: 1870-2010. J Allergy Clin Immunol 2015;136(1):3-13.

54. Quercia S, Candela M, Giuliani C, Turroni S, Luiselli D, Rampelli S, et al. From lifetime to evolution: timescales of human gut microbiota adaptation. Front Microbiol. 2014:5:587.

55. Wopereis H, Oozeer R, Knipping K, Belzer C, Knol J. The first thousand days - intestinal microbiology of early life: establishing a symbiosis. Pediatr Allergy Immunol. 2014:25(5):428-38.

56. Round JL, Mazmanian SK. The gut microbiota shapes intestinal immune responses during health and disease. Nat Rev Immunol. 2009;9(5):313-23.

57. Tanaka M, Nakayama J. Development of the gut microbiota in infancy and its impact on health in later life. Allergol Int. 2017;66(4):515-22
58. Rautava S, Ruuskanen O, Ouwehand A, Salminen S, Isolauri E. The hygiene hypothesis of atopic disease--an extended version. J Pediatr Gastroenterol Nutr. 2004;38(4):378-88

59. Gordon JI, Dewey KG, Mills DA, Medzhitov RM. The human gut microbiota and undernutrition. Sci Transl Med. 2012;4(137):137ps12.

60. Penders J, Gerhold K, Stobberingh EE, Thijs C, Zimmermann K, Lau S, et al. Establishment of the intestinal microbiota and its role for atopic dermatitis in early childhood. J Allergy Clin Immunol. 2013;132(3):601-7 e8,

61. Holloway JW, Prescott SL. The Origins of Allergic Disease. In: O'Hehir RE, Holgate ST, Sheikh A, editors. Middleton's Allergy Essentials. 1 ed. New York: Elsevier; 2017. p. 29-50.

62. Simpson MR, Brede G, Johansen J, Johnsen R, Storro O, Saetrom P, et al. Human Breast Milk miRNA, Maternal Probiotic Supplementation and Atopic Dermatitis in Offspring. PloS one. 2015;10(12):e0143496.

63. Day CP, Saksena S. Non-alcoholic steatohepatitis: definitions and pathogenesis. J Gastroenterol Hepatol. 2002;17 Suppl 3:S377-84.

64. Farrell GC, Larter CZ. Nonalcoholic fatty liver disease: from steatosis to cirrhosis. Hepatology. 2006;43(2 Suppl 1):S99-S112.

65. Angelico F, Del Ben M, Conti R, Francioso S, Feole K, Fiorello S, et al. Insulin resistance, the metabolic syndrome, and nonalcoholic fatty liver disease. J Clin Endocrinol Metab. 2005;90(3):1578-82.

66. Youssef WI, McCullough AJ. Steatohepatitis in obese individuals. Best Pract Res Clin Gastroenterol. 2002;16(5):733-47.

67. Murphy EF, Cotter PD, Hogan A, O'Sullivan O, Joyce A, Fouhy F, et al. Divergent metabolic outcomes arising from targeted manipulation of the gut microbiota in diet-induced obesity. Gut. 2013;62(2):220-6.

68. Harrison SA, Torgerson S, Hayashi PH. The natural history of nonalcoholic fatty liver disease: a clinical histopathological study. Am J Gastroenterol. 2003;98(9):2042-7.

69. Lewis JR, Mohanty SR. Nonalcoholic fatty liver disease: a review and update. Dig Dis Sci. 2010;55(3):560-78.

70. Loguercio C, De Simone T, Federico A, Terracciano F, Tuccillo C, Di Chicco $\mathrm{M}$, et al. Gut-liver axis: a new point of attack to treat chronic liver damage? Am J Gastroenterol. 2002;97(8):2144-6.

71. Lakhani SV, Shah HN, Alexander K, Finelli FC, Kirkpatrick JR, Koch TR. Small intestinal bacterial overgrowth and thiamine deficiency after Roux-en-Y gastric bypass surgery in obese patients. Nutr Res. 2008;28(5):293-8.

72. Madrid AM, Poniachik J, Quera R, Defilippi C. Small intestinal clustered contractions and bacterial overgrowth: a frequent finding in obese patients. Dig Dis Sci. 2011;56(1):155-60.

73. Soares JB, Pimentel-Nunes P, Roncon-Albuquerque R, Leite-Moreira A. The role of lipopolysaccharide/toll-like receptor 4 signaling in chronic liver diseases. Hepatol Int. 2010;4(4):659-72.

74. Bäckhed F, Ding H, Wang T, Hooper LV, Koh GY, Nagy A, et al. The gut microbiota as an environmental factor that regulates fat storage. Proc Natl Acad Sci U S A. 2004;101(44):15718-23.

75. Bäckhed F, Manchester JK, Semenkovich CF, Gordon JI. Mechanisms underlying the resistance to diet-induced obesity in germ-free mice. Proc Natl Acad Sci U S A. 2007;104(3):979-84.

76. Miyake Y, Yamamoto K. Role of gut microbiota in liver diseases. Hepatol Res. 2013;43(2):139-46

77. Gao B, Seki E, Brenner DA, Friedman S, Cohen JI, Nagy L, et al. Innate immunity in alcoholic liver disease. Am J Physiol Gastrointest Liver Physiol. 2011;300(4):G516-25.

78. Mokhtari Z, Gibson DL, Hekmatdoost A. Nonalcoholic Fatty Liver Disease, the Gut Microbiome, and Diet. Adv Nutr. 2017;8(2):240-52.

79. Schnabl B, Brenner DA. Interactions between the intestinal microbiome and liver diseases. Gastroenterology. 2014;146(6):1513-24.

80. Zhu L, Baker SS, Gill C, Liu W, Alkhouri R, Baker RD, et al. Characterization of gut microbiomes in nonalcoholic steatohepatitis (NASH) patients: a connection between endogenous alcohol and NASH. Hepatology. 2013;57(2):601-9.

81. Betrapally NS, Gillevet PM, Bajaj JS. Changes in the Intestinal Microbiome and Alcoholic and Nonalcoholic Liver Diseases: Causes or Effects? Gastroenterology. 2016;150(8):1745-55.e3.

82. Machado MV, Cortez-Pinto H. Diet, Microbiota, Obesity, and NAFLD: A Dangerous Quartet. Int J Mol Sci. 2016;17(4):481.

83. Boursier J, Mueller O, Barret M, Machado M, Fizanne L, Araujo-Perez F, et al. The severity of nonalcoholic fatty liver disease is associated with gut dysbiosis and shift in the metabolic function of the gut microbiota. Hepatology. 2016;63(3):764-75.

84. Henao-Mejia J, Elinav E, Thaiss CA, Licona-Limon P, Flavell RA. Role of the intestinal microbiome in liver disease. J Autoimmun. 2013;46:66-73.

85. Sreenivasa Baba C, Alexander G, Kalyani B, Pandey R, Rastogi S, Pandey A, et al. Effect of exercise and dietary modification on serum aminotransferase levels in patients with nonalcoholic steatohepatitis. J Gastroenterol Hepatol. 2006;21(1 Pt 1):191-8. 
86. Margariti E, Deutsch M, Manolakopoulos S, Papatheodoridis GV. Non-alcoholic fatty liver disease may develop in individuals with normal body mass index. Ann Gastroenterol. 2012;25(1):45-51.

87. Volynets V, Küper MA, Strahl S, Maier IB, Spruss A, Wagnerberger S, et al. Nutrition, intestinal permeability, and blood ethanol levels are altered in patients with nonalcoholic fatty liver disease (NAFLD). Dig Dis Sci. 2012;57(7): 1932-41.

88. Engstler AJ, Aumiller T, Degen C, Dürr M, Weiss E, Maier IB, et al. Insulin resistance alters hepatic ethanol metabolism: studies in mice and children with non-alcoholic fatty liver disease. Gut. 2016;65(9):1564-71.

89. Zhu L, Baker RD, Zhu R, Baker SS. Gut microbiota produce alcohol and contribute to NAFLD. Gut. 2016;65(7):1232.

90. Dumas ME, Barton RH, Toye A, Cloarec O, Blancher C, Rothwell A, et al. Metabolic profiling reveals a contribution of gut microbiota to fatty liver phenotype in insulin-resistant mice. Proc Natl Acad Sci U S A. 2006;103(33):12511-6.

91. Duarte SMB, Stefano JT, Miele L, Ponziani FR, Souza-Basqueira M, Okad LSRR, et al. Gut microbiome composition in lean patients with NASH is associated with liver damage independent of caloric intake: A prospective pilot study. Nutr Metab Cardiovasc Dis. 2018;28(4):369-84.

92. Ndugga N, Lightbourne TG, Javaherian K, Cabezas J, Verma N, Barritt ASt, et al Disparities between research attention and burden in liver diseases: implication on uneven advances in pharmacological therapies in Europe and the USA. BMJ open. 2017;7(3):e013620.

93. Wree A, Marra F. The inflammasome in liver disease. J Hepatol. 2016;65(5): 1055-6.

94. Milosevic I, Vujovic A, Barac A, Djelic M, Korac M, Radovanovic Spurnic A, et al. Gut-Liver Axis, Gut Microbiota, and Its Modulation in the Management of Liver Diseases: A Review of the Literature. Int J Mol Sci. 2019;20(2).

95. Sarin SK, Pande A, Schnabl B. Microbiome as a therapeutic target in alcohol-related liver disease. J Hepatol. 2019;70(2):260-72.

96. Buzzetti E, Kalafateli M, Thorburn D, Davidson BR, Thiele M, Gluud LL, et al. Pharmacological interventions for alcoholic liver disease (alcohol-related liver disease): an attempted network meta-analysis. Cochrane Database Syst Rev. 2017;3:CD011646.

97. Louvet A, Mathurin P. Alcoholic liver disease: mechanisms of injury and targeted treatment. Nat Rev Gastroenterol Hepatol. 2015;12(4):231-42.

98. Schneider AC, Machado AB, de Assis AM, Hermes DM, Schaefer PG, Guizzo R, et al. Effects of Lactobacillus rhamnosus GG on hepatic and serum lipid profiles in zebrafish exposed to ethanol. Zebrafish. 2014;11(4):371-8

99. Schneider AC, Gregorio C, Uribe-Cruz C, Guizzo R, Malysz T, Faccioni-Heuse $\mathrm{MC}$, et al. Chronic exposure to ethanol causes steatosis and inflammation in zebrafish liver. World J Hepatol. 2017;9(8):418-26

100. Bruch-Bertani JP, Uribe-Cruz C, Pasqualotto A, Longo L, Ayres R, Beskow $\mathrm{CB}$, et al. Hepatoprotective Effect of Probiotic Lactobacillus rhamnosus GG Through the Modulation of Gut Permeability and Inflammasomes in a Model of Alcoholic Liver Disease in Zebrafish. J Am Coll Nutr. 2019:1-8.

101. Tsochatzis EA, Bosch J, Burroughs AK. Liver cirrhosis. Lancet. 2014:383(9930):1749-61

102. Moon AM, Singal AG, Tapper EB. Contemporary Epidemiology of Chronic Liver Disease and Cirrhosis. Clin Gastroenterol Hepatol. 2019.

103. Riordan SM, McIver CJ, Wakefield D, Duncombe VM, Thomas MC, Bolin TD, Small intestinal mucosal immunity and morphometry in luminal overgrowth of indigenous gut flora. Am J Gastroenterol. 2001;96(2):494-500.

104. Bures J, Cyrany J, Kohoutova D, Forstl M, Rejchrt S, Kvetina J, et al. Small intestinal bacterial overgrowth syndrome. World J Gastroenterol. 2010;16 (24):2978-90

105. Wu GD, Chen J, Hoffmann C, Bittinger K, Chen YY, Keilbaugh SA, et al. Linking long-term dietary patterns with gut microbial enterotypes. Science. 2011:334(6052):105-8

106. Morgun A, Dzutsev A, Dong X, Greer RL, Sexton DJ, Ravel J, et al. Uncovering effects of antibiotics on the host and microbiota using transkingdom gene networks. Gut. 2015;64(11):1732-43.

107. Wiest R, Lawson M, Geuking M. Pathological bacterial translocation in liver cirrhosis. J Hepatol. 2014;60(1):197-209.

108. Bauer TM, Steinbruckner B, Brinkmann FE, Ditzen AK, Schwacha H, Aponte $\mathrm{JJ}$, et al. Small intestinal bacterial overgrowth in patients with cirrhosis: prevalence and relation with spontaneous bacterial peritonitis. Am J Gastroenterol. 2001;96(10):2962-7.

109. Chang CS, Chen GH, Lien HC, Yeh HZ. Small intestine dysmotility and bacterial overgrowth in cirrhotic patients with spontaneous bacterial peritonitis. Hepatology. 1998;28(5):1187-90

110. Teltschik Z, Wiest R, Beisner J, Nuding S, Hofmann C, Schoelmerich J, et al. Intestinal bacterial translocation in rats with cirrhosis is related to compromised Paneth cell antimicrobial host defense. Hepatology. 2012;55(4):1154-63.
111. Bajaj JS, Hylemon PB, Ridlon JM, Heuman DM, Daita K, White MB, et al Colonic mucosal microbiome differs from stool microbiome in cirrhosis and hepatic encephalopathy and is linked to cognition and inflammation. Am J Physiol Gastrointest Liver Physiol. 2012;303(6):G675-85.

112. Chen Y, Yang F, Lu H, Wang B, Chen Y, Lei D, et al. Characterization of fecal microbial communities in patients with liver cirrhosis. Hepatology. 2011;54(2):56272.

113. Bajaj JS, Heuman DM, Hylemon PB, Sanyal AJ, White MB, Monteith P, et al. Altered profile of human gut microbiome is associated with cirrhosis and its complications. J Hepatol. 2014;60(5):940-7.

114. Lin RS, Lee FY, Lee SD, Tsai YT, Lin HC, Lu RH, et al. Endotoxemia in patients with chronic liver diseases: relationship to severity of liver diseases, presence of esophageal varices, and hyperdynamic circulation. J Hepatol. 1995;22(2):165-72.

115. Qin N, Yang F, Li A, Prifti E, Chen Y, Shao L, et al. Alterations of the human gut microbiome in liver cirrhosis. Nature. 2014;513(7516):59-64.

116. Krieger D, Krieger S, Jansen O, Gass P, Theilmann L, Lichtnecker H. Manganese and chronic hepatic encephalopathy. Lancet. 1995;346(8970):270-4.

117. Jalan R, Gines P, Olson JC, Mookerjee RP, Moreau R, Garcia-Tsao G, et al Acute-on chronic liver failure. J Hepatology. 2012;57(6):1336-48.

118. Bajaj JS, O'Leary JG, Reddy KR, Wong F, Biggins SW, Patton H, et al. Survival in infection-related acute-on-chronic liver failure is defined by extrahepatic organ failures. Hepatology. 2014;60(1):250-6.

119. O'Leary JG, Reddy KR, Garcia-Tsao G, Biggins SW, Wong F, Fallon MB, et al NACSELD acute-on-chronic liver failure (NACSELD-ACLF) score predicts 30-day survival in hospitalized patients with cirrhosis. Hepatology. 2018.

120. Moreau R, Jalan R, Gines P, Pavesi M, Angeli P, Cordoba J, et al. Acute-onchronic liver failure is a distinct syndrome that develops in patients with acute decompensation of cirrhosis. Gastroenterology. 2013;144(7):1426-37, 37 e1-9.

121. Fischer J, Silva TE, Soares ESPE, Colombo BS, Silva MC, Wildner LM, et al. From stable disease to acute-on-chronic liver failure: Circulating cytokines are related to prognosis in different stages of cirrhosis. Cytokine. 2017;91:162-9.

122. Hensley MK, Deng JC. Acute on Chronic Liver Failure and Immune Dysfunction: A Mimic of Sepsis. Semin Respir Crit Care Med. 2018;39(5):588-97.

123. Chen Y, Guo J, Qian G, Fang D, Shi D, Guo L, et al. Gut dysbiosis in acute-onchronic liver failure and its predictive value for mortality. J Gastroenterol Hepatol. 2015;30(9):1429-37.

124. Bajaj JS, Vargas HE, Reddy KR, Lai JC, O’Leary JG, Tandon P, et al. Association Between Intestinal Microbiota Collected at Hospital Admission and Outcomes of Patients With Cirrhosis. Clin Gastroenterol Hepatol.. 2019;17(4):756-65 e3.

125. Liu Q, Duan ZP, Ha DK, Bengmark S, Kurtovic J, Riordan SM. Synbiotic modulation of gut flora: effect on minimal hepatic encephalopathy in patients with cirrhosis. Hepatology. 2004;39(5):1441-9.

126. Bajaj JS, Heuman DM, Hylemon PB, Sanyal AJ, Puri P, Sterling RK, et al. Randomised clinical trial: Lactobacillus GG modulates gut microbiome, metabolome and endotoxemia in patients with cirrhosis. Aliment Pharmacol Ther 2014:39(10):1113-25

127. Bajaj JS. The role of microbiota in hepatic encephalopathy. Gut Microbes 2014:5(3):397-403

128. Koutnikova H, Genser B, Monteiro-Sepulveda M, Faurie JM, Rizkalla S, Schrezenmeir J, et al. Impact of bacterial probiotics on obesity, diabetes and non-alcoholic fatty liver disease related variables: a systematic review and meta-analysis of randomised controlled trials. BMJ Open. 2019;9(3):e017995.

129. Dalal R, McGee RG, Riordan SM, Webster AC. Probiotics for people with hepatic encephalopathy. The Cochrane database of systematic reviews. 2017;2:CD008716.

130. Wahlstrom A. Outside the liver box: The gut microbiota as pivotal modulator of liver diseases. Biochimica et biophysica acta Molecular basis of disease. 2019;1865(5):912-9.

131. Schirbel A, Fiocchi C. Inflammatory bowel disease: Established and evolving considerations on its etiopathogenesis and therapy. J Dig Dis. 2010;11(5):266-76.

132. Kostic AD, Xavier RJ, Gevers D. The microbiome in inflammatory bowel disease: current status and the future ahead. Gastroenterology. 2014;146(6):1489-99.

133. Orel R, Kamhi Trop T. Intestinal microbiota, probiotics and prebiotics in inflammatory bowel disease. World J Gastroenterol. 2014;20(33):11505-24.

134. Rolhion N, Carvalho FA, Darfeuille-Michaud A. OmpC and the sigma(E) regulatory pathway are involved in adhesion and invasion of the Crohn's disease-associated Escherichia coli strain LF82. Mol Microbiol. 2007;63(6):1684-700.

135. Hold GL, Smith M, Grange C, Watt ER, El-Omar EM, Mukhopadhya I. Role of the gut microbiota in inflammatory bowel disease pathogenesis: what have we learnt in the past 10 years? World J Gastroenterol. 2014;20(5):1192-210.

136. Torres J, Hu J, Seki A, Eisele C, Nair N, Huang R, et al. Infants born to mother with IBD present with altered gut microbiome that transfers abnormalities of the adaptive immune system to germ-free mice. Gut. 2019

137. Sun M, Wu W, Liu Z, Cong Y. Microbiota metabolite short chain fatty acids, GPCR, and inflammatory bowel diseases. J Gastroenterol. 2017;52(1):1-8. 
138. Forbes A, Escher J, Hébuterne X, Kłęk S, Krznaric Z, Schneider S, et al. ESPEN guideline: Clinical nutrition in inflammatory bowel disease. Clin Nutr. 2017;36(2):321-47.

139. Moayyedi P, Surette MG, Kim PT, Libertucci J, Wolfe M, Onischi C, et al. Fecal Microbiota Transplantation Induces Remission in Patients With Active Ulcerative Colitis in a Randomized Controlled Trial. Gastroenterology. 2015;149(1):102-9.e6.

140. Paramsothy S, Kamm MA, Kaakoush NO, Walsh AJ, van den Bogaerde J, Samuel D, et al. Multidonor intensive faecal microbiota transplantation for active ulcerative colitis: a randomised placebo-controlled trial. Lancet. 2017;389(10075): 1218-28.

141. Francino MP. Antibiotics and the Human Gut Microbiome: Dysbioses and Accumulation of Resistances. Front Microbiol. 2015;6:1543

142. Agamennone V, Krul CAM, Rijkers G, Kort R. A practical guide for probiotics applied to the case of antibiotic-associated diarrhea in The Netherlands. BMC Gastroenterol. 2018;18(1):103.

143. Lessa FC, Mu Y, Bamberg WM, Beldavs ZG, Dumyati GK, Dunn JR, et al Burden of Clostridium difficile infection in the United States. N Engl J Med. 2015;372(9):825-34.

144. Almeida R, Gerbaba T, Petrof EO. Recurrent Clostridium difficile infection and the microbiome. J Gastroenterol. 2016;51(1):1-10.

145. Zhang S, Palazuelos-Munoz S, Balsells EM, Nair H, Chit A, Kyaw MH. Cost of hospital management of Clostridium difficile infection in United States-a meta-analysis and modelling study. BMC Infect Dis. 2016;16(1):447.

146. Theriot CM, Young VB. Interactions Between the Gastrointestinal Microbiome and Clostridium difficile. Annu Rev Microbiol. 2015;69:445-61.

147. Mills JP, Rao K, Young VB. Probiotics for prevention of Clostridium difficile infection. Curr Opin Gastroenterol. 2018;34(1):3-10.

148. Evans CT, Johnson S. Prevention of Clostridium difficile Infection With Probiotics. Clin Infect Dis. 2015;60 Suppl 2:S122-8.

149. Koretz RL. Probiotics in Gastroenterology: How Pro Is the Evidence in Adults? Am J Gastroenterol. 2018;113(8):1125-36.

150. Goldenberg JZ, Yap C, Lytvyn L, Lo CK, Beardsley J, Mertz D, et al. Probiotics for the prevention of Clostridium difficile-associated diarrhea in adults and children. Cochrane Database Syst Rev. 2017;12:CD006095

151. Enck P, Mazurak N. Dysbiosis in Functional Bowel Disorders. Ann Nutr Metab. 2018;72(4):296-306

152. Yoon YK, Suh JW, Kang EJ, Kim JY. Efficacy and safety of fecal microbiota transplantation for decolonization of intestinal multidrug-resistant microorganism carriage: beyond. Ann Med. 2019:1-11.

153. Hungin AP, Mulligan C, Pot B, Whorwell P, Agréus L, Fracasso P, et al. Systematic review: probiotics in the management of lower gastrointestinal symptoms in clinical practice -- an evidence-based international guide. Aliment Pharmacol Ther. 2013;38(8):864-86

154. Dupont HL. Review article: evidence for the role of gut microbiota in irritable bowel syndrome and its potential influence on therapeutic targets. Aliment Pharmacol Ther. 2014;39(10):1033-42.

155. Lee BJ, Bak YT. Irritable bowel syndrome, gut microbiota and probiotics. J Neurogastroenterol Motil. 2011;17(3):252-66.

156. Dale HF, Rasmussen SH, Asiller Ö, Lied GA. Probiotics in Irritable Bowel Syndrome: An Up-to-Date Systematic Review. Nutrients. 2019;11(9).

157. Didari T, Mozaffari S, Nikfar S, Abdollahi M. Effectiveness of probiotics in irritable bowel syndrome: Updated systematic review with meta-analysis. World J Gastroenterol. 2015;21(10):3072-84.

158. Moayyedi P, Ford AC, Talley NJ, Cremonini F, Foxx-Orenstein AE, Brandt LJ, et al. The efficacy of probiotics in the treatment of irritable bowel syndrome: a systematic review. Gut. 2010;59(3):325-32.

159. Barbara G, Cremon C, Azpiroz F. Probiotics in irritable bowel syndrome: Where are we? Neurogastroenterol Motil. 2018;30(12):e13513

160. Enck P, Aziz Q, Barbara G, Farmer AD, Fukudo S, Mayer EA, et al. Irritable bowel syndrome. Nat Rev Dis Primers. 2016;2:16014.

161. Hojsak I. Probiotics in Functional Gastrointestinal Disorders. Adv Exp Med Biol. 2019;1125:121-37.

162. Camilleri M. Management Options for Irritable Bowel Syndrome. Mayo Clin Proc. 2018;93(12):1858-72

163. Ford AC, Moayyedi P, Chey WD, Harris LA, Lacy BE, Saito YA, et al. American College of Gastroenterology Monograph on Management of Irritable Bowel Syndrome. Am J Gastroenterol. 2018;113(Suppl 2):1-18.

164. Guarner F, Sanders M, Eliakin R, Fedorak R, Gangl A, Garish J. Diretrizes Mundiais da Organização Mundial de Gastroenterologia: probióticos and prebióticos. Available from: http://www.worldgastroenterology.org/UserFiles/file/ guidelines/probiotics-and-prebiotics-portuguese-20172017

165. Currò D, Ianiro G, Pecere S, Bibbò S, Cammarota G. Probiotics, fibre and herbal medicinal products for functional and inflammatory bowel disorders. $\mathrm{Br}$ J Pharmacol. 2017;174(11):1426-49
166. Ford AC, Harris LA, Lacy BE, Quigley EMM, Moayyedi P. Systematic review with meta-analysis: the efficacy of prebiotics, probiotics, synbiotics and antibiotics in irritable bowel syndrome. Aliment Pharmacol Ther. 2018;48(10):1044-60.

167. Ford AC, Quigley EM, Lacy BE, Lembo AJ, Saito YA, Schiller LR, et al. Efficacy of prebiotics, probiotics, and synbiotics in irritable bowel syndrome and chronic idiopathic constipation: systematic review and meta-analysis. Am J Gastroenterol. 2014;109(10):1547-61; quiz 6, 62.

168. Camilleri M, Ford AC, Mawe GM, Dinning PG, Rao SS, Chey WD, et al. Chronic constipation. Nat Rev Dis Primers. 2017:3:17095

169. Ohkusa T, Koido S, Nishikawa Y, Sato N. Gut Microbiota and Chronic Constipation: A Review and Update. Front Med (Lausanne). 2019;6:19.

170. Huang L, Zhu Q, Qu X, Qin H. Microbial treatment in chronic constipation. Sci China Life Sci. 2018;61(7):744-52.

171. Alam NH, Ashraf H. Treatment of infectious diarrhea in children. Paediatr Drugs. 2003;5(3):151-65.

172. Guarino A, Ashkenazi S, Gendrel D, Vecchio AL, Shamir R, Szajewska H. European Society for Paediatric Gastroenterology, Hepatology, and Nutrition/ European Society for Paediatric Infectious Diseases Evidence-based Guidelines for the Management of Acute Gastroenteritis in Children in Europe: Update 2014. J Pediatr Gastroenterol Nutr. 2014.

173. Barbuti RC. Diarreias agudas. Aspectos clínicos, etiológicos e terapêuticos. RBM. Revista Brasileira de Medicina (Rio de Janeiro). 2008;34(1):3-12.

174. Kosek M, Bern C, Guerrant RL. The global burden of diarrhoeal disease, as estimated from studies published between 1992 and 2000. Bull World Health Organ. 2003;81(3):197-204

175. Verdu EF, Riddle MS. Chronic gastrointestinal consequences of acute infectious diarrhea: evolving concepts in epidemiology and pathogenesis. Am J Gastroenterol. 2012;107(7):981-9.

176. Franceschi F, Scaldaferri F, Riccioni ME, Casagranda I, Forte E, Gerardi V, et al. Management of acute dyarrhea: current and future trends. Eur Rev Med Pharmacol Sci. 2014;18(14):2065-9.

177. Guarino A, Dupont C, Gorelov AV, Gottrand F, Lee JK, Lin Z, et al. The management of acute diarrhea in children in developed and developing areas: from evidence base to clinical practice. Expert Opin Pharmacother. 2012;13(1):17-26.

178. Lo Vecchio A, Buccigrossi V, Fedele MC, Guarino A. Acute Infectious Diarrhea. Adv Exp Med Biol. 2019;1125:109-20.

179. Gutierrez-Castrellon P, Lopez-Velazquez G, Diaz-Garcia L, Jimenez-Gutierrez C, Mancilla-Ramirez J, Estevez-Jimenez J, et al. Diarrhea in preschool children and Lactobacillus reuteri: a randomized controlled trial. Pediatrics. 2014;133(4):e904-

180. Graves NS. Acute gastroenteritis. Prim Care. 2013;40(3):727-41

181. Brandt KG, Castro Antunes MM, Silva GA. Acute diarrhea: evidence-based management. J Pediatr (Rio J). 2015;91(6 Suppl 1):S36-43.

182. Farthing M, Salam M. Acute diarrhea in adults and children: a global perspective. World Gastroenterology Organization Global Guidelines. 2012.

183. Barr W, Smith A. Acute diarrhea. Am Fam Physician. 2014;89(3):180-9.

184. Riddle MS, DuPont HL, Connor BA. ACG Clinical Guideline: Diagnosis, Treatment, and Prevention of Acute Diarrheal Infections in Adults. Am J Gastroenterol. 2016;111(5):602-22.

185. Liu Y, Tran DQ, Fatheree NY, Marc Rhoads J. Lactobacillus reuteri DSM 17938 differentially modulates effector memory $\mathrm{T}$ cells and Foxp3+ regulatory $\mathrm{T}$ cells in a mouse model of necrotizing enterocolitis. Am J Physiol Gastrointest Liver Physiol. 2014;307(2):G177-86.

186. Liu Y, Fatheree NY, Mangalat N, Rhoads JM. Lactobacillus reuteri strains reduce incidence and severity of experimental necrotizing enterocolitis via modulation of TLR 4 and NF- $x$ B signaling in the intestine. Am J Physiol Gastrointest Liver Physiol. 2012;302(6):G608-17.

187. Ojetti V, Gigante G, Gabrielli M, Ainora ME, Mannocci A, Lauritano EC, et al. The effect of oral supplementation with Lactobacillus reuteri or tilactase in lactose intolerant patients: randomized trial. Eur Rev Med Pharmacol Sci. 2010;14(3):163-70.

188. Shornikova AV, Casas IA, Isolauri E, Mykkänen H, Vesikari T. Lactobacillus reuteri as a therapeutic agent in acute diarrhea in young children. J Pediatr Gastroenterol Nutr. 1997;24(4):399-404

189. Shornikova AV, Casas IA, Mykkänen H, Salo E, Vesikari T. Bacteriotherapy with Lactobacillus reuteri in rotavirus gastroenteritis. Pediatr Infect Dis J. 1997;16(12):1103-7.

190. Weizman Z, Asli G, Alsheikh A. Effect of a probiotic infant formula on infections in child care centers: comparison of two probiotic agents. Pediatrics. 2005;115(1):5-9.

191. Francavilla R, Lionetti E, Castellaneta S, Ciruzzi F, Indrio F, Masciale A, et al. Randomised clinical trial: Lactobacillus reuteri DSM 17938 vs. placebo in children with acute diarrhoea--a double-blind study. Aliment Pharmacol Ther. 2012;36(4):363-9 
192. Szajewska H, Guarino A, Hojsak I, Indrio F, Kolacek S, Shamir R, et al. Use of probiotics for management of acute gastroenteritis: a position paper by the ESPGHAN Working Group for Probiotics and Prebiotics. J Pediatr Gastroenterol Nutr. 2014;58(4):531-9.

193. Szajewska H, Urbańska M, Chmielewska A, Weizman Z, Shamir R. Meta-analysis: Lactobacillus reuteri strain DSM 17938 (and the original strain ATCC 55730) for treating acute gastroenteritis in children. Benef Microbes. 2014;5(3):285-93.

194. Capurso L. Thirty Years of Lactobacillus rhamnosus GG: A Review. J Clin Gastroenterol. 2019;53 Suppl 1:S1-S41

195. Cruchet S, Furnes R, Maruy A, Hebel E, Palacios J, Medina F, et al. The Use of Probiotics in Pediatric Gastroenterology: A Review of the Literature and Recommendations by Latin-American Experts. Paediatr Drugs. 2015.

196. Feizizadeh S, Salehi-Abargouei A, Akbari V. Efficacy and safety of Saccharomyces boulardii for acute diarrhea. Pediatrics. 2014;134(1):e176-91.

197. Szajewska H, Skórka A, Dylag M. Meta-analysis: Saccharomyces boulardii for treating acute diarrhoea in children. Aliment Pharmacol Ther. 2007:25(3):257-64.

198. Szajewska H, Skórka A, Ruszczyński M, Gieruszczak-Białek D. Meta-analysis: Lactobacillus GG for treating acute diarrhoea in children. Aliment Pharmacol Ther. 2007;25(8):871-81.

199. Shane AL, Mody RK, Crump JA, Tarr PI, Steiner TS, Kotloff K, et al. 2017 Infectious Diseases Society of America Clinical Practice Guidelines for the Diagnosis and Management of Infectious Diarrhea. Clin Infect Dis. 2017;65(12):e45-e80.

200. Coelho LGV, Marinho JR, Genta R, Ribeiro LT, Passos MDCF, Zaterka S, et al. IVth Brazilian Consensus Conference on Helicobacter pylori infection. Arq Gastroenterol. 2018;55(2):97-121.

201. Graham DY, Dore MP. Update on the Use of Vonoprazan: A Competitive Acid Blocker. Gastroenterology. 2018;154(3):462-6.

202. Li M, Oshima T, Horikawa T, Tozawa K, Tomita T, Fukui H, et al. Systematic review with meta-analysis: Vonoprazan, a potent acid blocker, is superior to proton-pump inhibitors for eradication of clarithromycin-resistant strains of Helicobacter pylori. Helicobacter. 2018;23(4):e12495

203. Malfertheiner P, Megraud F, O’Morain CA, Gisbert JP, Kuipers EJ, Axon AT, et al. Management of Helicobacter pylori infection-the Maastricht V/Florence Consensus Report. Gut. 2017;66(1):6-30.

204. Francavilla R, Polimeno L, Demichina A, Maurogiovanni G, Principi B, Scaccianoce $\mathrm{G}$, et al. Lactobacillus reuteri strain combination In Helicobacter pylori infection: a randomized, double-blind, placebo-controlled study. J Clin Gastroenterol. 2014;48(5):407-13.

205. Lü M, Yu S, Deng J, Yan Q, Yang C, Xia G, et al. Efficacy of Probiotic Supplementation Therapy for Helicobacter pylori Eradication: A Meta-Analysis of Randomized Controlled Trials. PLoS One. 2016;11(10):e0163743.
206. Bhatt AP, Redinbo MR, Bultman SJ. The role of the microbiome in cancer development and therapy. CA Cancer J Clin. 2017;67(4):326-44.

207. Joukar F, Mavaddati S, Mansour-Ghanaei F, Samadani AA. Gut Microbiota as a Positive Potential Therapeutic Factor in Carcinogenesis: an Overview of Microbiota-Targeted Therapy. J Gastrointest Cancer. 2019.

208. Górska A, Przystupski D, Niemczura MJ, Kulbacka J. Probiotic Bacteria: A Promising Tool in Cancer Prevention and Therapy. Curr Microbiol. 2019;76(8):939-49.

209. Pope JL, Tomkovich S, Yang Y, Jobin C. Microbiota as a mediator of cancer progression and therapy. Transl Res. 2017;179:139-54.

210. van den Nieuwboer M, Claassen E. Dealing with the remaining controversies of probiotic safety. Benef Microbes. 2019:1-12.

211. Klement RJ, Pazienza V. Impact of Different Types of Diet on Gut Microbiota Profiles and Cancer Prevention and Treatment. Medicina (Kaunas). 2019;55(4).

212. Homayouni A, Bastani P, Ziyadi S, Mohammad-Alizadeh-Charandabi S, Ghalibaf M, Mortazavian AM, et al. Effects of probiotics on the recurrence of bacterial vaginosis: a review. J Low Genit Tract Dis. 2014;18(1):79-86.

213. Castro A, González M, Tarín JJ, Cano A. [Role of probiotics in Obstetrics and Gynecology]. Nutr Hosp. 2015;31 Suppl 1:26-30.

214. Sherwin E, Dinan TG, Cryan JF. Recent developments in understanding the role of the gut microbiota in brain health and disease. Ann N Y Acad Sci. 2017

215. Sarkar A, Lehto SM, Harty S, Dinan TG, Cryan JF, Burnet PW. Psychobiotics and the Manipulation of Bacteria-Gut-Brain Signals. Trends Neurosci. 2016;39(11):763-81.

216. Dinan TG, Cryan JF. Melancholic microbes: a link between gut microbiota and depression? Neurogastroenterol Motil. 2013;25(9):713-9.

217. Oleskin AV, Shenderov BA. Probiotics and Psychobiotics: the Role of Microbial Neurochemicals. Probiotics Antimicrob Proteins. 2019.

218. Fiocchi A, Pawankar R, Cuello-Garcia C, Ahn K, Al-Hammadi S, Agarwal A, et al. World Allergy Organization-McMaster University Guidelines for Allergic Disease Prevention (GLAD-P): Probiotics. World Allergy Organ J. 2015;8(1):4

219. Kalliomäki M, Salminen S, Arvilommi H, Kero P, Koskinen P, Isolauri E. Probiotics in primary prevention of atopic disease: a randomised placebo-controlled trial. Lancet. 2001;357(9262):1076-9.

220. Abrahamsson TR, Jakobsson T, Böttcher MF, Fredrikson M, Jenmalm MC, Björkstén B, et al. Probiotics in prevention of IgE-associated eczema: double-blind, randomized, placebo-controlled trial. J Allergy Clin Immunol. 2007;119(5):1174-80

221. Forsberg A, West CE, Prescott SL, Jenmalm MC. Pre- and probiotics for allergy prevention: time to revisit recommendations? Clin Exp Allergy. 2016;46(12):1506-21.

222. Sanders ME. Impact of probiotics on colonizing microbiota of the gut. J Clin Gastroenterol. 2011;45 (Suppl):S115-9. 